
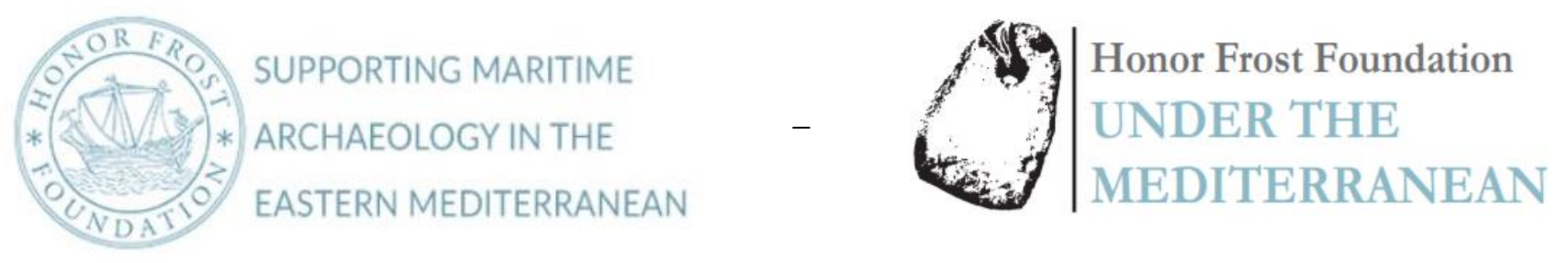

'Under the Mediterranean'The Honor Frost Foundation Conference on Mediterranean Maritime Archaeology 20th $-23_{\text {rd }}$ October 2017 Short Report Series.

doi: https://doi.org/10.33583/utm2020.12

(C) 2020 The Author

\title{
Salamis Harbour Project, 2016-2017. Summary of Results
}

\author{
Y.G. Lolos ${ }^{\text {a }}$ A. Simossi ${ }^{b}$
}

aHellenic Institute of Marine Archaeology and University of Ioannina, ilolos@cc.uoi.gr •Ephorate of Underwater Antiquities, Hellenic Ministry of Culture and Sports, asimosi@ culture.gr

The aim of this concise report is to present and assess the results of the Salamis Harbour Project, 20162017, initiated with a research grant from the Honor Frost Foundation (for 2016). This is a three-year (2016-2018) interdisciplinary project of systematic underwater survey and documentation-work, by the Hellenic Institute of Marine Archaeology in collaboration with the Ephorate of Underwater Antiquities of the Hellenic Ministry of Culture and Sports, with the active involvement of the Laboratory of Marine Geology and Physical Oceanography of the University of Patras under Prof. G. Papatheodorou, and having, for the first time, as the main focus, the Bay of Ambelaki and adjacent area in the Straits of Salamis, Greece, a seascape loaded with great importance for Athenian and Greek history.

\section{Key words}

Salamis, Ambelaki, underwater survey, geoarchaeology, harbour-town

In November-December 2016 and in June-July 2017 an underwater survey, as part of a three-year collaborative interdisciplinary project between the Ephorate of Underwater Antiquities (EUA) of the Hellenic Ministry of Culture and Sports and the Hellenic Institute of Marine Archaeology (HIMA), was conducted off the eastern coast of Salamis in the Saronic Gulf (namely in the area of Ambelaki-Kynosoura, in Figs 1, 2, 4, 5, 28) under the direction of Dr Angeliki Simossi, Head of the Ephorate, and Yannos G. Lolos, Professor of Archaeology at 
the University of Ioannina and President of the Institute, 1 with the involvement of the Laboratory of Marine Geology and Physical Oceanography of the University of Patras under Professor George Papatheodorou, and thanks to financial support (for the 2016 campaign) from the Honor Frost Foundation.

It should be noted that this is the first systematic underwater reconnaissance to be initiated by Greek institutions (with the participation of a 25 member team, see Fig. 3), in a heavily polluted marine environment (including the seabed), yet in a crucial area of historical importance (Figs 5, 28).

With regard to the history of marine research in the Straits of Salamis, it should be remembered that a pioneering underwater investigation was carried out in the Winter of 1884 in the area between Kynosoura-PsyttaleiaKeratsini, under the direction of the great Greek prehistorian Christos Tsountas, with the involvement of traditional divers (see Lolos 2003, 13-27;. Catsambis,2006, 104-107).

The main focus of the 2016 research was the inner (western) part of the present-day Bay of Ambelaki, formed by the peninsulas of Pounta (ancient Kolouris) and Kynosoura (Figs 4-5). This is the commercial and military harbour of the Classical and Hellenistic town or demos of Salamis and certainly the closest and most vital harbour of the city-state of Athens, after those of Piraeus (i.e. Kantharos, Zea, and Mounichia). It is also the gathering place of the united Greek fleet on the eve of the great sea-battle of $480 \mathrm{BC}$, found in close proximity to well-known monuments to the naval success: the polyandreion or burial mound of the victors and the tropaion (trophy), on the long peninsula of Kynosoura (see I.G. II2, 1035, lines 33-34). References to the ancient port of Salamis occur in the works of the geographer Pseudo-Scylax (of the 4th century BC), the geographer Strabo (of the $1_{\text {st }}$ century BC-1 $1_{\text {st }}$ centuryAD) and the traveller Pausanias (of the 2 nd century AD).

Occasional mention of the antiquities in the harbour of Salamis, at Ambelaki, is found in works by several travellers, historians, archaeologists and other scholars of the 19 th and 20 th centuries, most notably by P. Rediadis (1902) and Ph. Negris (1904), while some of the submerged ancient remains in the Bay are marked, in a rudimentary manner, on old maps by: W. M. Leake (1841), H. G. Lolling (1884), German military cartographers (1889/1891), E. Curtius and J. A. Kaupert (1895, here in Fig. 5) and the Greek naval cartographers M. Matthaiopoulos and A. Chrysanthis (1916).

\section{The 2016 Survey}

One of the main results of the 2016 underwater survey was the identification/documentation of submerged ancient remains on all three sides (north, west and south) of the Bay of Ambelaki (Figs 7, 8, 11). These are found above or under water, according to tidal changes in sea-level, which reaches its lowest point of about $0.5 \mathrm{~min}$ the month of February, i.e. as a result, several submerged remains are visible only at certain times of the year at low tides (Figs 6, 16, 17, 19).

The ancient architectural remains, which have been identified on the shore and in shallow waters, in the inner Bay, comprise port installations, fortification works and various other structures. By employing a combination 
of methods and techniques (aerial photography with a drone, photogrammetry, topographical and architectural documentation), 2 the first underwater archaeological map of the area, with all visible elements, was constructed in 2016.

An essential part of the 2016 survey off Salamis was the geophysical research, carried out by a team from the University of Patras, and using a side-scan sonar, a marine magnetometer (Fig. 9), and a special device with an attached underwater camera. The main aims of this investigation were the identification of elements of archaeological interest on the sea-bottom and the determination of the coast-line in the bay in the Classical period. The high-quality digital data collected during the first geophysical survey have been of great value for the reconstruction of the coastal palaeogeography of the area.

Of great interest is an 'enclosed' or protected area (now partly a marsh), with special functions, in the northwest part of the present-day Bay of Ambelaki (Figs 10-11). It is defined, on the south, by an impressive, long wall (Fig. 10), of likely Late Classical/Hellenistic date, extending c. $160 \mathrm{~m}$ (with a width of $4 \mathrm{~m}$ ) and ending in a strong, well-built round tower (Figs 12-13), with a diameter of $7 \mathrm{~m}$., of a type well-known from other fortified harbour-sites, e.g. at Thasos, Halieis (Porto Cheli), and Phalasarna in Crete; while, on the east, this special area is bordered by a much later (and certainly post-Roman) 'raised' mole, $48 \mathrm{~m}$ long in a N-S axis, in front of the Old Kriezis House, carelessly constructed with ancient building material (dressed blocks and other large stones) coming from one or more adjacent structures, and probably lying, partly at least, on ancient foundations (Fig. 14). This later mole, whose exact date cannot be determined at present, is clearly marked on maps of the end of the $19_{\text {th }}$ century.

Immediately west of the later mole, at a distance of 2.30-2.50m., surface clearing of the blackish mud has revealed a continuous row of at least 15 large ashlar-blocks, stretching over $10 \mathrm{~m}$. in a N-S axis, and apparently belonging to the base of a strong, well-built ancient structure (Figs 14-15). Selective tests have showed that the thickness of the ashlar blocks reaches $0.50 \mathrm{~m}$.

In the same (north/northwest) area, at some distance to the west of the later (post-Roman) mole, a large submerged ancient building (or other structure) of oblong shape (Fig. 16), in a N-S axis, and of unknown character, measuring $21 \times 9.20 \mathrm{~m}$., has been surveyed.

On the south side of the inner Bay, the submerged remains, documented in the course of the 2016 survey, include (as seen from northwest to southeast): a pier or breakwater of rubble (Fig. 17), with a width of $3.70 \mathrm{~m}$, running for $39 \mathrm{~m}$, in a NE-SW direction; a mole, parallel to a modern mole, with a length of $40 \mathrm{~m}$, in a NE-SW axis; also a wall, c. $30 \mathrm{~m}$ long and almost parallel to the present-day coast line, with an attached square tower-like structure $(6 \times 6 \mathrm{~m})$.

Finally, within the context of the 2016 survey, a large quantity of diagnostic surface finds was collected, in nine sectors, on the north and west side of the Bay of Ambelaki. The surface collection has yielded numerous sherds from commercial jars, basins and other vases of various periods, a bronze coin of Corinth (of the 4 th century 
BC) and some small objects (Fig. 18). The largest proportion of the surface potsherds (including many fragments of plain and Attic Black-Glazed pots) can be securely dated to the Classical and Hellenistic periods, apparently associated with the function of the main buildings and other installations in the coastal zone of the harbour-town of Salamis during the flourishing phases of Athenian history.

Among the ceramic material collected in 2016, the pottery dating from Late Roman/Early Byzantine times can be associated with a settlement of those times, parts of which have been revealed by rescue excavations carried out by the Greek Archaeological Service in the coastal zone, on the west and north side of the Bay of Ambelaki.

\section{The 2017 Survey}

In June-July 2017 documentation and clearing work on subsided architectural remains on the west and north side of the inner Bay was continued, using as a base the underwater archaeological map made in 2016.

On the west side, the existence of a massive square tower (c. $8 \times 8 \mathrm{~m})$ has been documented (Figs 19-20), built of large blocks and apparently connected with the wider (inner) fortification system of the Classical-Hellenistic city and harbour. Parts of this system are: the (now) submerged long wall to the north of the square tower, already surveyed in 2016, and also a stretch of the city-fortification, with two square towers (comparable in size and structure to the submerged one), running N-S, at some distance to the west of it, on land.

To make an addition at this point: An important result of our survey on nearby land, in conjunction with the study of the defences of the historic harbour, has been the identification of further stretches (previously unnoticed by other researchers) of a long line of the outer fortification wall of the Classical-Hellenistic city of Salamis, running on the western part of the peninsula of Kynosoura, west of the Magoula hill (with the polyandrion), and apparently protecting its harbour from the south.

In 2017 special priority was given to the underwater research, comprising both clearing work and testing, using both a hydro-lift and the techniques of land excavation (or "wet excavation"), in the area marked by the long post-Roman mole, on the north side of the inner Bay of Ambelaki.

Just to the west of it, investigation of the row of large ashlar blocks was continued, i.e. part of the foundation of a strong subsided building, first revealed in 2016, now running for (at least) $13 \mathrm{~m}$ in a N-S direction and certainly turning, at its south end, to the east (where the foundation is arranged in two courses). It is, in all probability, a section of the base (krepis) of an important ancient structure of public character, whose plan cannot be detected at this stage (Figs 21-23).

The form of the krepis, together with the other architectural elements and movable finds, in conjunction with the discovery (in 1882) of a marble base of a statue with a dedicatory inscription to Salamis, the Nymph (I.G. II 2 1955), in the immediate neighbourhood, lead us to the provisional identification of the structure as part of a temple complex or stoa, in use in the Late Roman period, and probably founded in older, Late ClassicalHellenistic times. 
Of special importance, among other finds retrieved from the destruction layer and mainly associated with the final phase in the building's use (in the 3rd century AD) are: a drum of an unfluted stone column ( $0.35 \mathrm{~m}$ in diameter) (Figs 24-25) and various marble finds including parts of a rectangular altar, a stele, statues and vessels (Fig. 26); also fragments of Late Roman clay lamps, from known Athenian shops, including that of Leonteus, and other vases (Fig. 27).

On the current evidence, the base of the large structure that is emerging from the mud (of the present-day seabottom) must have been one of the last ancient public buildings, set in the seaside zone of the harbour-town of Salamis, possibly one of those seen and mentioned by Pausanias in his Description of Greece $(1.35 .3,1.36 .1)$ in the late 2 nd century AD.

The very important results of the marine geophysical survey, conducted in July 2017 in the Bay of Ambelaki and the Straits, are summarized by Professor George Papatheodorou and his colleagues in the Appendix, accompanying this concise report.

\section{Epilogue}

The most important aspect of the 2016-2017 archaeological survey was the documentation of submerged port installations and various other structures of commercial, cultic and military character, and dating from Classical to Late Roman and even later times, on all three sides of the inner Bay of Ambelaki.

The fortified northwestern part of the present-day Bay, defined by the long wall and signalled by the two towers, at its limits, is the prime evidence for the identification of that crucial area as an exclusive seaside zone of the harbour-town of Salamis, certainly an Athenian territory for most of the Classical-Hellenistic period.

This new evidence, seen within the wider topography of the Straits, and supplemented by the information from ancient historical, literary and epigraphical sources, leaves no doubt about the pivotal function of the Bay as the assembly and eventually launching point of the Greek fleet (of over 300 triremes) against the invading Persian armada in $480 \mathrm{BC}$.

We are fairly hopeful that future underwater discoveries in the course of our survey and excavation in the wider area of Ambelaki will comprise finds, of all kinds, some of which may prove to have a close association with major events of Athenian history of the 5 th century BC, or perhaps finds related to monuments to the epic seabattle on neighbouring land.

\section{Endnotes}

\footnotetext{
${ }^{1}$ Also, with Dr. Christina Marabea and Ms. Myrto Michalis (M.A.) as chief archaeologists.

${ }^{2}$ Achieved by Mr. Vassilis Mentoyannis, Fotini Vlachaki (Postgraduate Specialization Diploma, N.T.U.A.) and Lena Diamanti.
} 


\section{Appendix}

\section{Salamis Project: A Marine Geoarchaeological Approach}

George Papatheodorou, Maria Geraga, Nikos Georgiou, Dimitris Christodoulou, Elias Fakiris and Xenophon Dimas

Laboratory of Marine Geology \& Physical Oceanography

Geology Department

University of Patras

\section{Introduction}

The Laboratory of Marine Geology \& Physical Oceanography (Geology Department, University of Patras) has joined the research group of archaeologists directed by Prof. Yannos Lolos and Dr Angeliki Simossi, conducting surveying off Salamis with the use of marine geophysical techniques. Marine geophysical techniques have proved useful tools for surveying underwater cultural heritage sites. They are fast, flexible, reliable and non-destructive methods. The aims of the 2017 marine geophysical surveying were to evaluate the evolution of the coastal palaeogeography of the Ambelakia-Kynosoura area focusing on the localization of the Classical coastline (at about 500 years BC) and also to detect, locate and map buried targets of potential archaeological significance. Within this concept, the 2017 marine geophysical surveying was conducted together with the Innomar's Student Project 2017. This proved to be beneficial for the research since the equipment of INNOMAR is capable of acquiring profiles of high resolution, which after processing could provide 3D images of the recorded sites.

\section{Survey design}

Our vessel Maria-Dimitra was used for the survey. SES-2000 sub-bottom profiler is a dual frequency parametric innovative system capable of reaching $1 \mathrm{~cm}$ of vertical resolution in extremely shallow water. The high frequency is useful for detecting the seafloor with great accuracy, while the low frequency is useful for penetrating up to $40 \mathrm{~m}$ into the sediments. The SES-2000 and the motion sensor were installed on the starboard side with the use of Innomar's easily manageable bracket system. The operational frequency set at $10 \mathrm{kHz}$, taken into consideration the water depth and the texture of the seafloor. In total 403 lines with a total length of $130 \mathrm{~km}$ were surveyed (Fig. 28). The maximum penetration achieved was $5 \mathrm{~m}$ due to the sandy seabed which prevented the sound from reaching deeper. In order to acquire greater accuracy, the profiles were tide corrected according to the tide gauge of Peiraeus Harbour, with a mean sea tide of $4 \mathrm{~cm}$.

Together with the SES, the research vessel was specially modified to deploy a Kongsberg Geopulse Chirp Sub bottom profiler on the port side, an ITER systems Bathyswath multibeam echosounder and a side-scan sonar 
EG\&G 272TD, in order to fully cover every aspect of the area. The synthetic interpretation of the data acquired from all the above equipment together with SES-2000 is expected to bring great results to the scientific community. For the positioning and navigation, a DGPS (Hemisphere VS100) and Hypack software were used (Fig. 29).

\section{Preliminary data results and analysis}

A detailed bathymetric map of Kynosoura Bay was constructed (Fig. 30). The bay (part of the Straits of Salamis) is generally shallow, reaching a maximum depth of $-32 \mathrm{~m}$. In the western area (Ambelakia), the seafloor gradually degrades seawards. The Kynosoura peninsula is rocky and steeper than the rest of the area. East of Akra Pounta a hard substrate appears, that resembles the geomorphology of the Kynosoura peninsula.

On the seismic profiles acquired many buried acoustic anomalies were recorded. The most prominent seismic unit on the seismic profiles, where the majority of the acoustic anomalies were detected, was recorded lying just below the seafloor (Fig. 31). The acoustic signature of this unit is distinct and is characterized by an almost acoustic transparency of about $0-5 \mathrm{~m}$ depth (Fig. 31). The base of the unit recorded as a reflector (Seismic Reflector 1) with micro-relief and of medium amplitude, which allowed further acoustic penetration (Fig. 31). Locally internal parallel reflectors of weak amplitude were recorded within the unit.

The main capability of the SES-2000 is the detection of buried targets (Fig. 32). Unit 1 contains 400 targets buried in different depths. The origin of these acoustic anomalies could be natural or artificial. However, all the targets were digitized and distinguished based on continuity, shape, coherence, and higher reflectivity, but without taking into consideration their spatial distribution. Among them 92 targets were selected to be further analysed, despite their spatial distribution. Almost all the selected targets were detected in a limited area of the nearshore zone of Ambelakia Bay, landwards the palaeoshorelineat $6.5 \mathrm{~m}$. The spatial distribution of all the targets is not included here.

\section{Preliminary conclusions and future work}

Considering that this is the first geophysical survey in the harbour of the Battle of Salamis and the Straits and the project is in an early stage, the findings appear of great importance. This survey has followed the downscaling methodology proposed in SASMAP (SASMAP Guideline Manual 2). The Bay of Ambelakia has proved to be a very promising area for surveying. The marine geophysical survey team of 2017, using nondestructive tools, managed to: (i) detect and map indexes of palaeoshorelines suggesting the extent of the prehistoric and historical coastal zone; (ii) detect and map geomorphological features most probably related to the submerged foundations revealed from the recent archaeological survey-work; and (iii) detect and map the sedimentary layer, which is considered to correspond to the ancient seafloor of the 5th century BC. According to the acquired profiles this layer hosts a multitude of acoustic anomalies.

The use of the SES-2000 high-resolution sub-bottom profiler has proved essential for their detection and mapping. SES-2000 amazingly has detected targets in extremely shallow waters. The origin of these targets 
has not been defined yet. However, all of them are located within marine sedimentary deposits in an area bordered by the present coastline and the location of the $6.5 \mathrm{~m}$ palaeoshoreline. The ability to develop 3D representations of them enables us to construct a data base with the most promising targets of archaeological value. Among others, two targets judging from their shape, coherence, and higher reflectivity, appear as the most promising and they were proposed for excavation (Figs 32-33).

Despite the fact that the Ambelakia Bay is heavily affected by modern shipyards and other installations, the historical and archaeological significance of the area as well as the present opportunity given in such an accessible and shallow environment, renders the seascape a top priority for experimentation and innovative technology testing. The geophysical survey has pointed out specific sites for future archaeological excavation and surveying. Furthermore, sediment coring is proposed for the estimation of the sedimentation rate and the ${ }_{14} \mathrm{C}$ dating of the findings.

\section{Acknowledgments}

We would like to thank Prof. Yannos Lolos and Dr Angeliki Simossi and their colleagues (Fig. 3) for the excellent cooperation. We would also like to thank INNOMAR (Sabine Mueller, Jens Lowag) for choosing funding the Salamis Project to be implemented and all the support. Special thanks go to Peter Huembs who helped in issues regarding the installation of the instrument, collection and interpretation of the data as well as being available for all questions at any time.

\section{References}

Catsambis,2006, 104-107

Lolos 2003, 13-27 


\section{Figures}

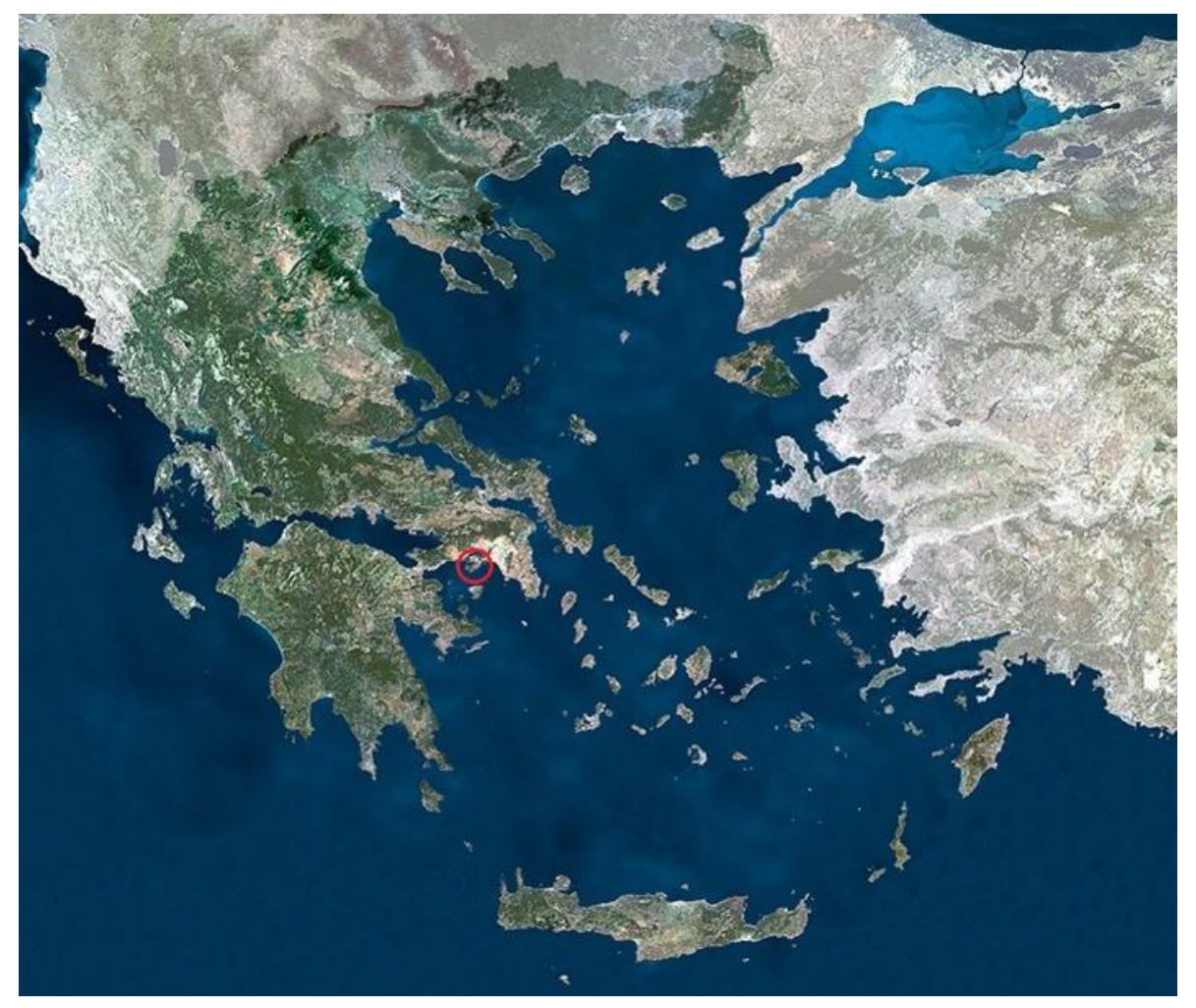

Fig. 1. Google Earth map of Greece, with the island of Salamis (in red circle).

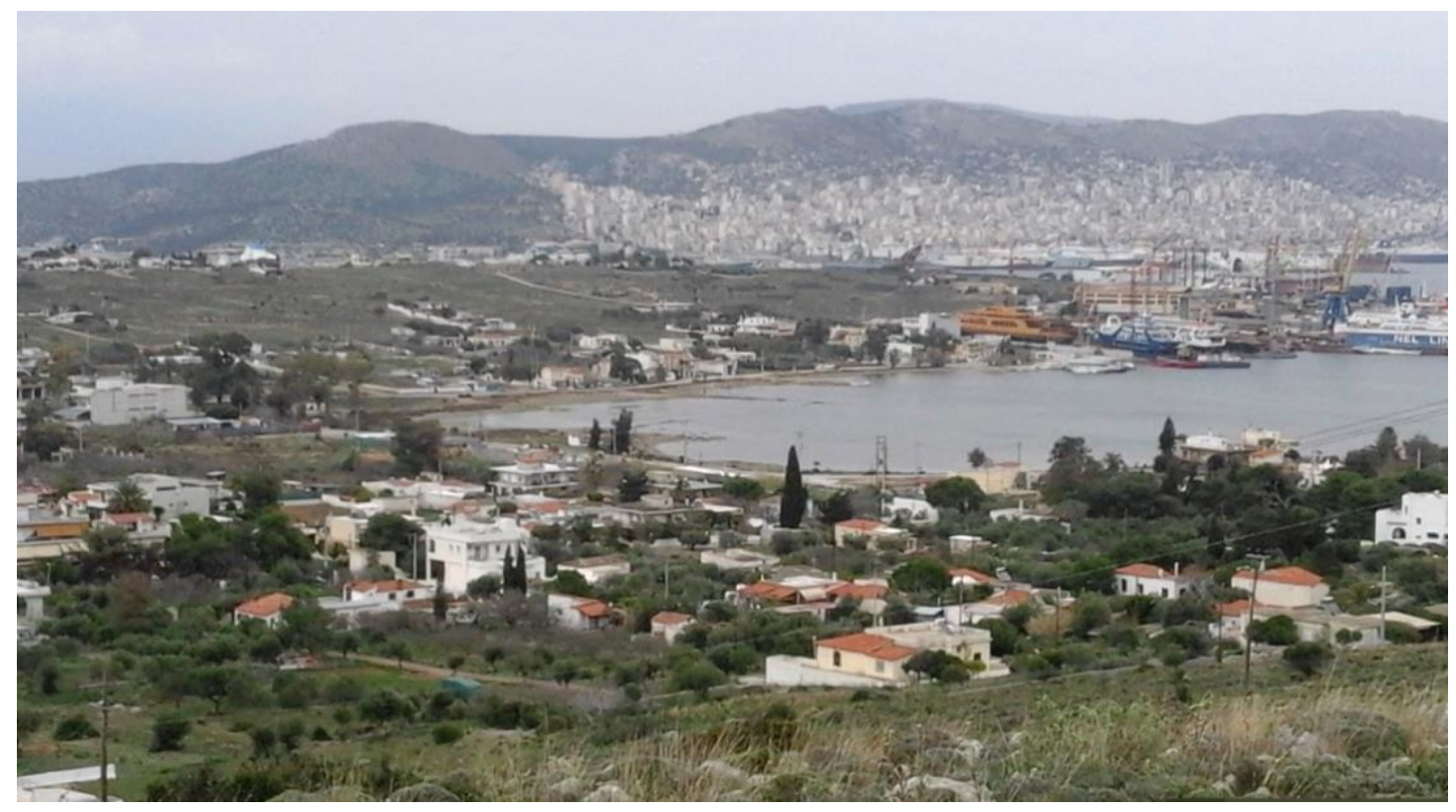

Fig. 2. Salamis. The Bay of Ambelaki, from the southwest. 


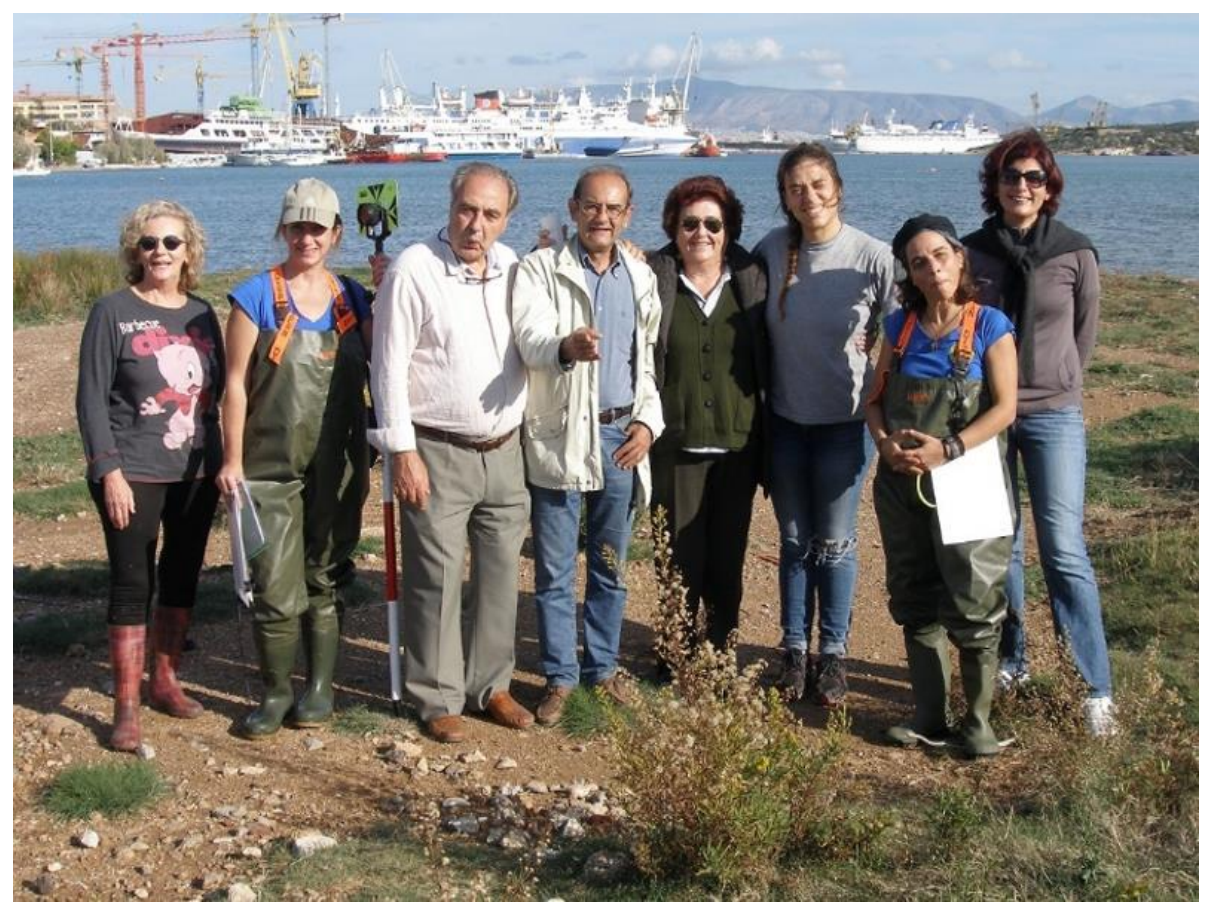

Fig. 3. Salamis, Ambelaki. Chief members of the joint team, at the beginning of the 2016 campaign.

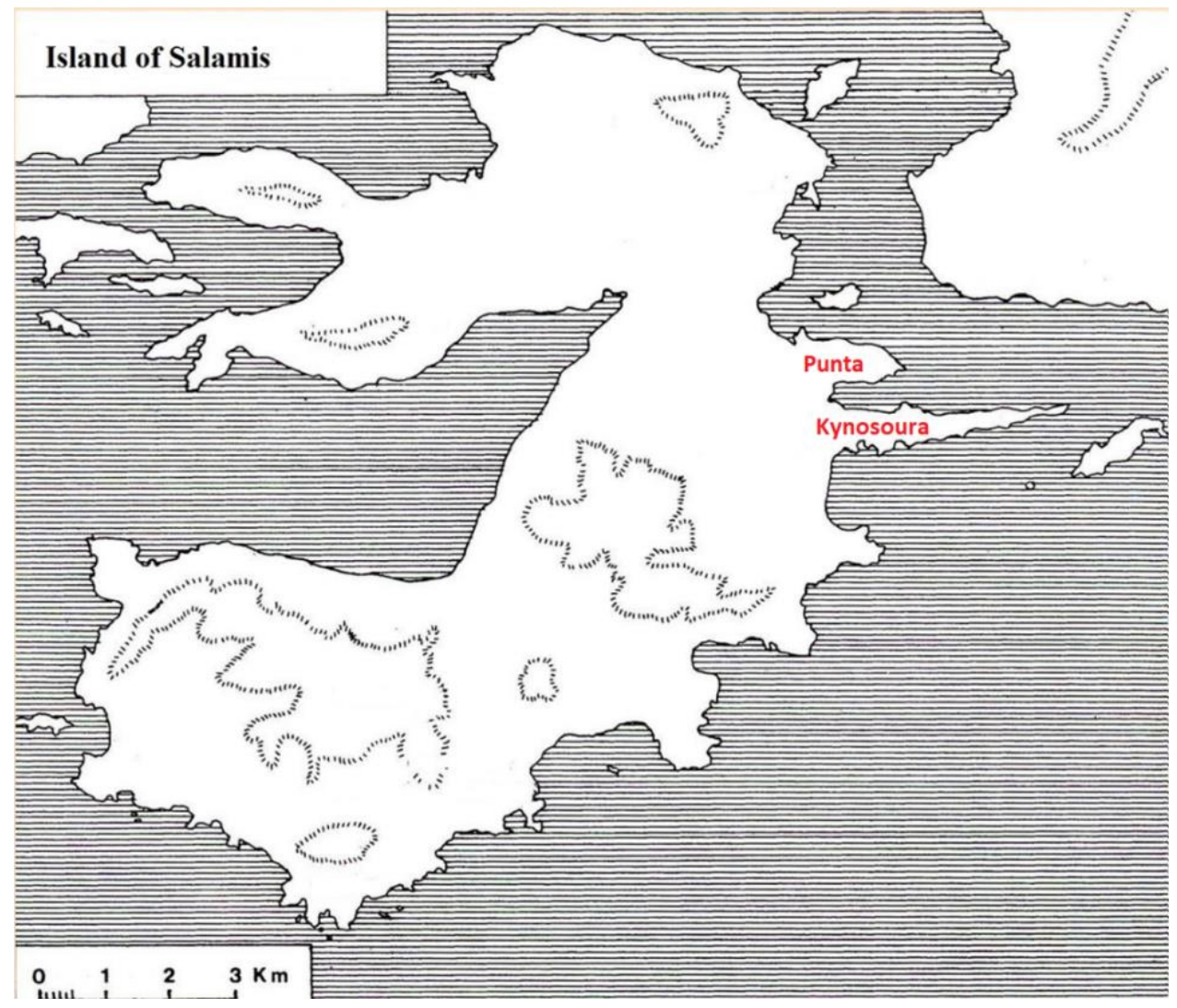

Fig. 4. Salamis. Map showing the peninsulas of Punta and Kynosoura. 


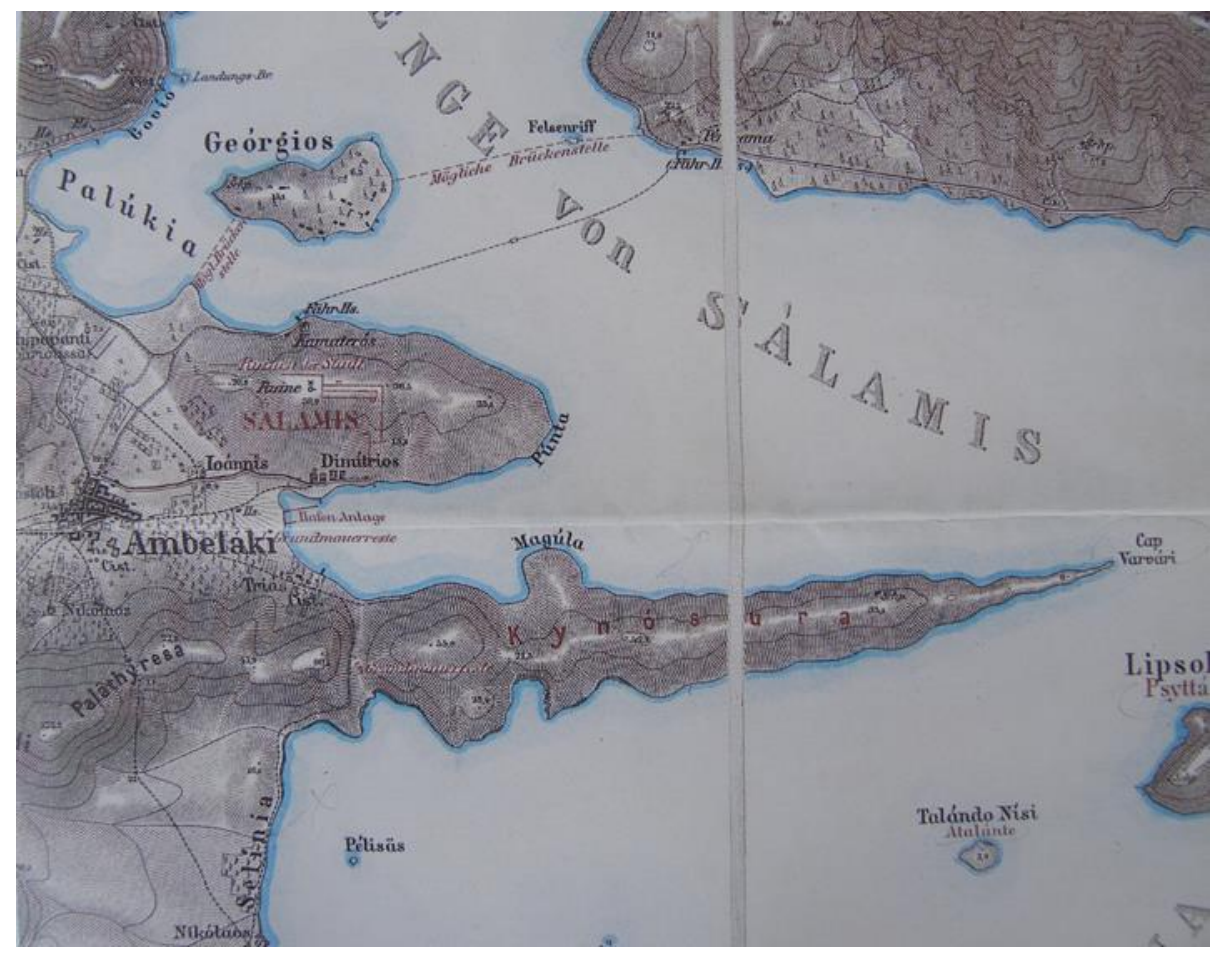

Fig. 5. Salamis. The Bay of Ambelaki, in E. Curtius and J.A. Kaupert, Karten von Attika (1895), Bl. XXI (detail).

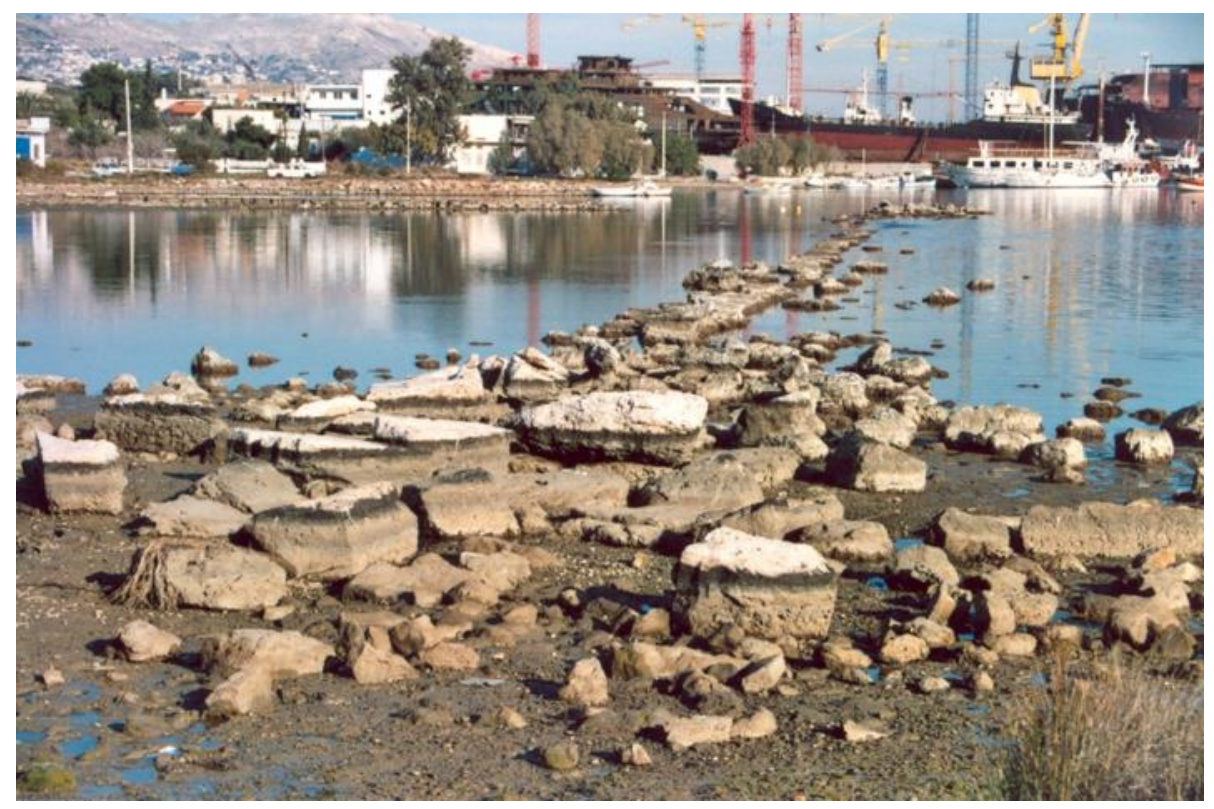

Fig. 6. Salamis, Bay of Ambelaki. Submerged long wall and other remnants of fortifications in the inner part of the Bay, at low tide (from west).

\section{Please insert Fig. 7}

Fig. 7. Salamis, Bay of Ambelaki. General plan of the inner Bay, with submerged antiquities, surveyed at the beginning of the 2016 campaign. 


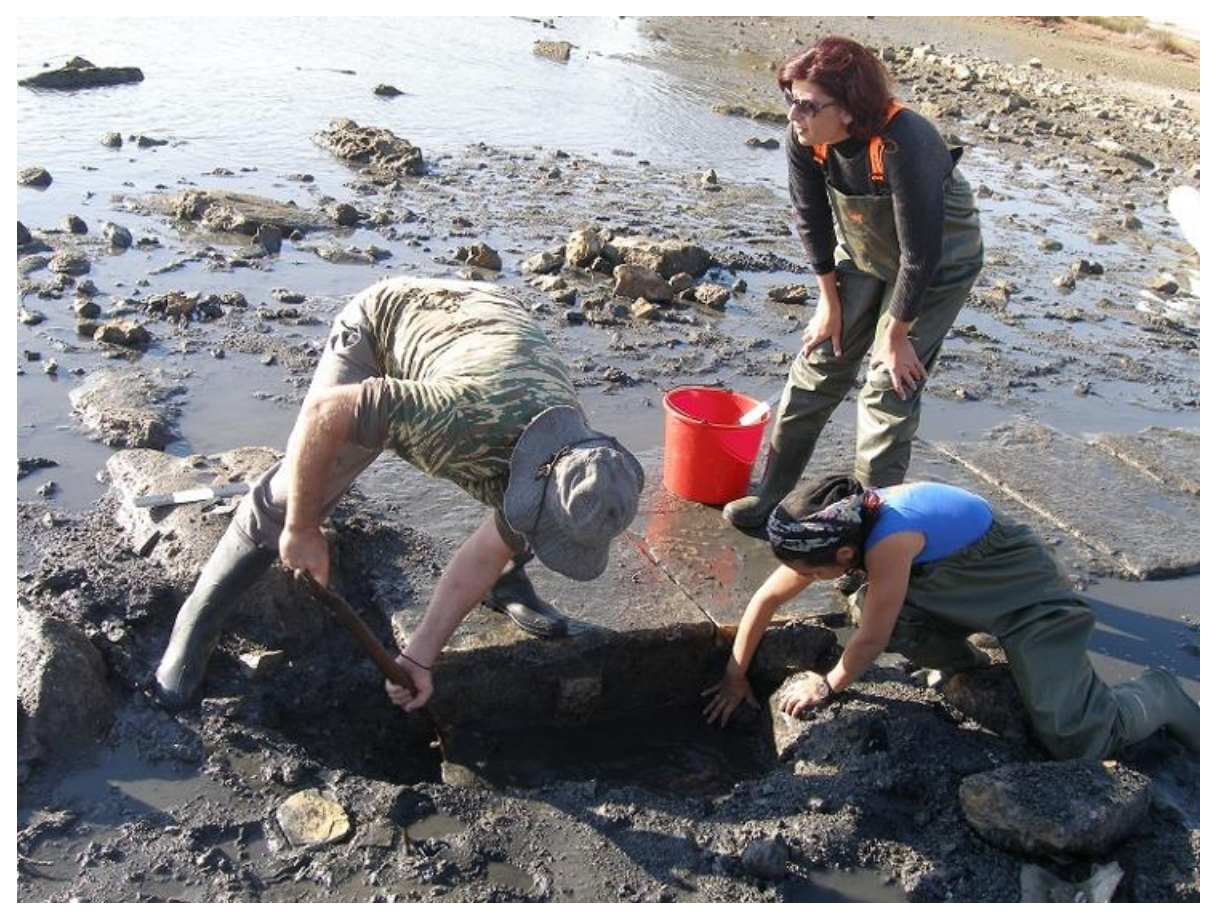

Fig. 8. Salamis, Bay of Ambelaki. Clearing works in the area with the foundation of a strong subsided building, on the north side of the inner Bay (2016).

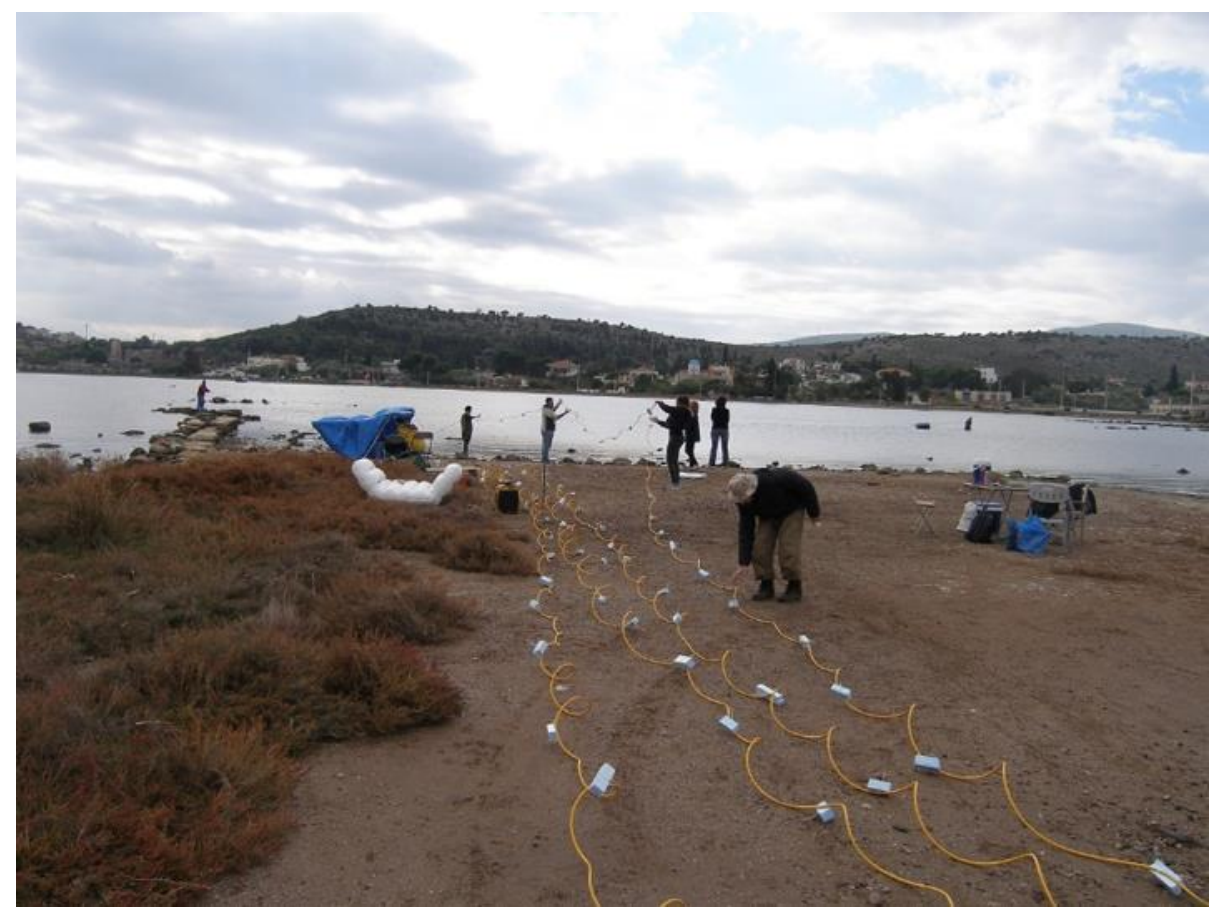

Fig. 9. Salamis, Bay of Ambelaki. Geophysical research: Deployment of a marine magnometer (2016). 


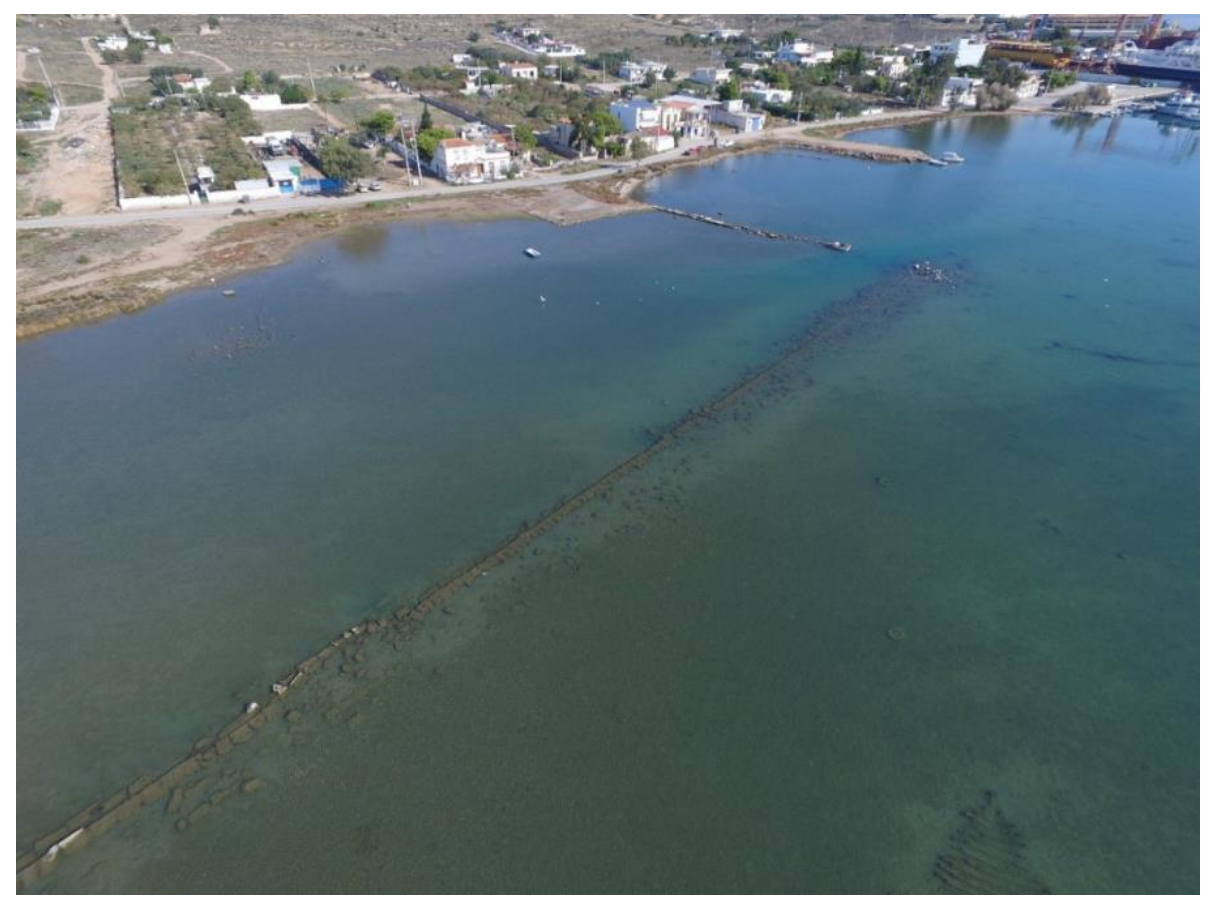

Fig. 10. Salamis, Bay of Ambelaki. Aerial view of the submerged long wall in the northwestern part of the inner Bay, from southwest. 


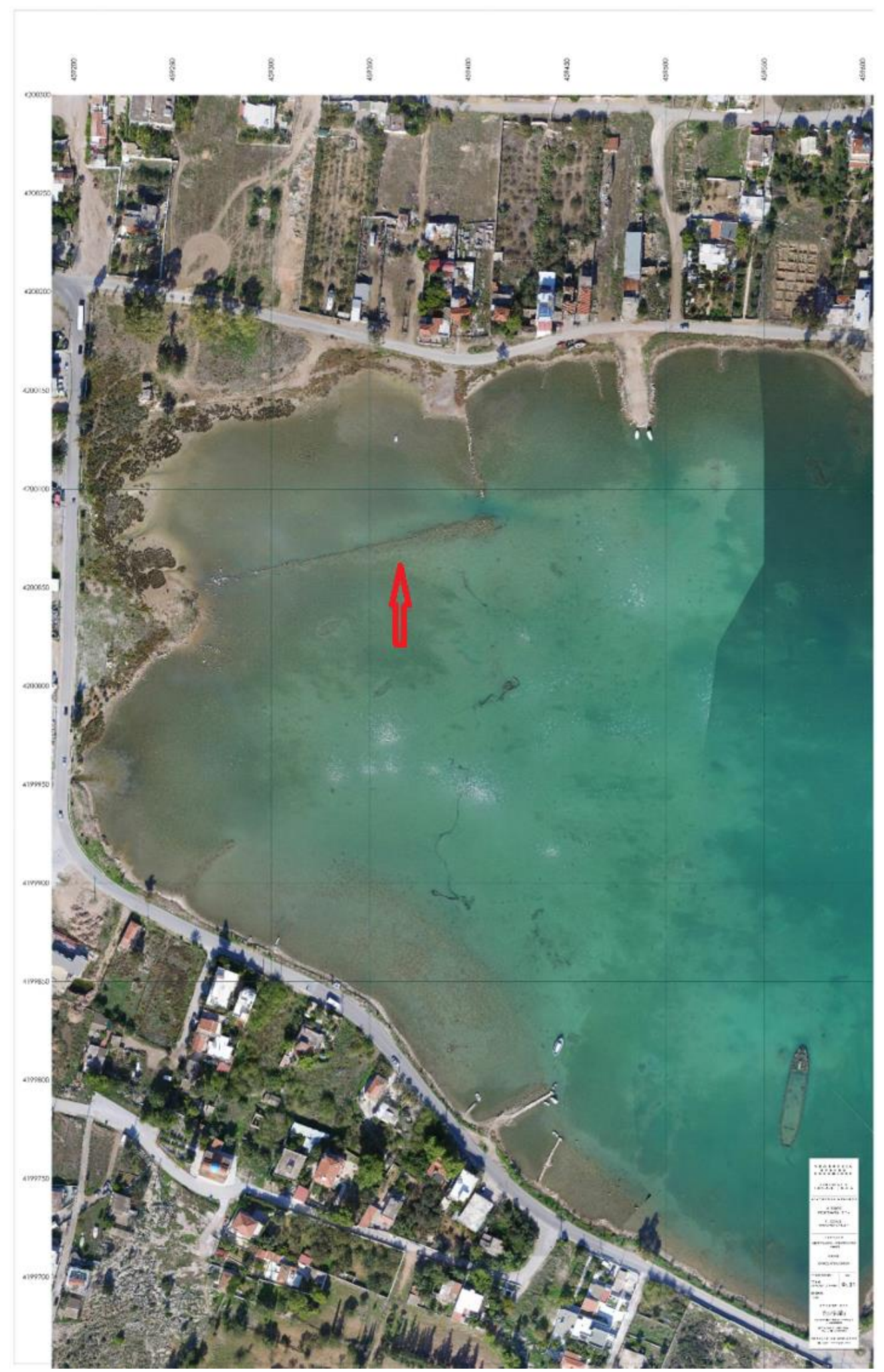

Fig. 11. Salamis, Bay of Ambelaki. Aerial view of the inner Bay, with submerged antiquities. 


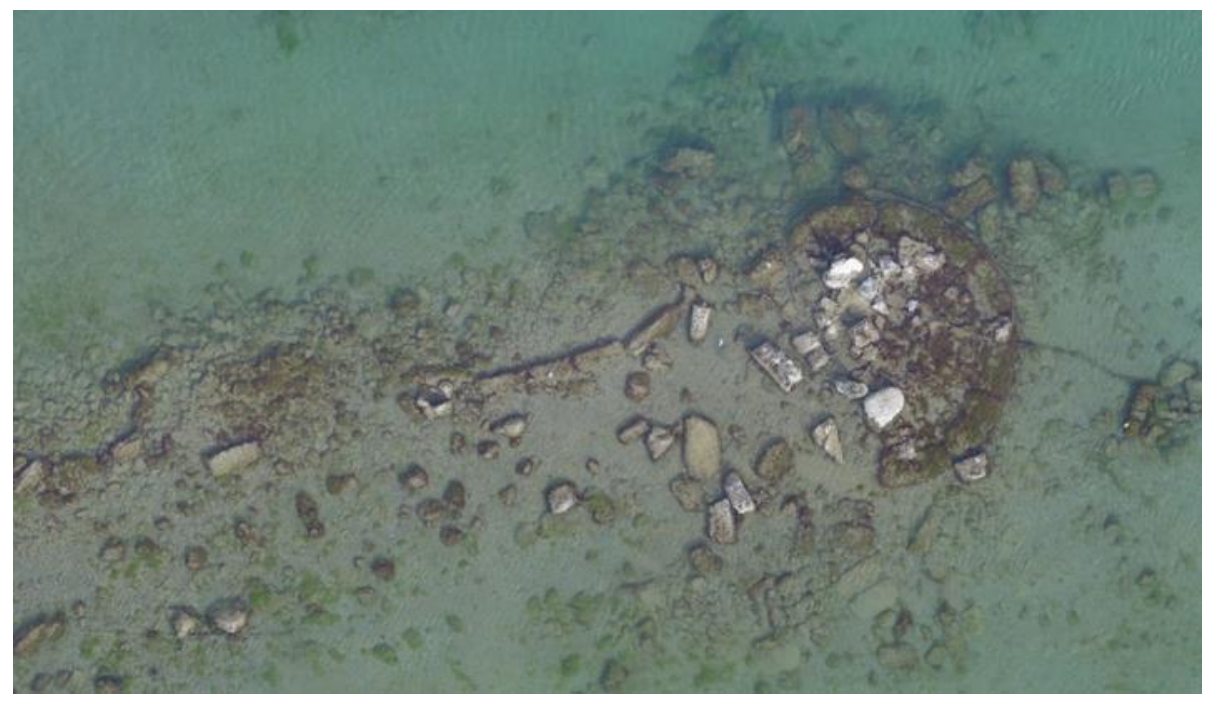

Fig. 12. Salamis, Bay of Ambelaki. Aerial view of the submerged round tower at the end of the long wall.

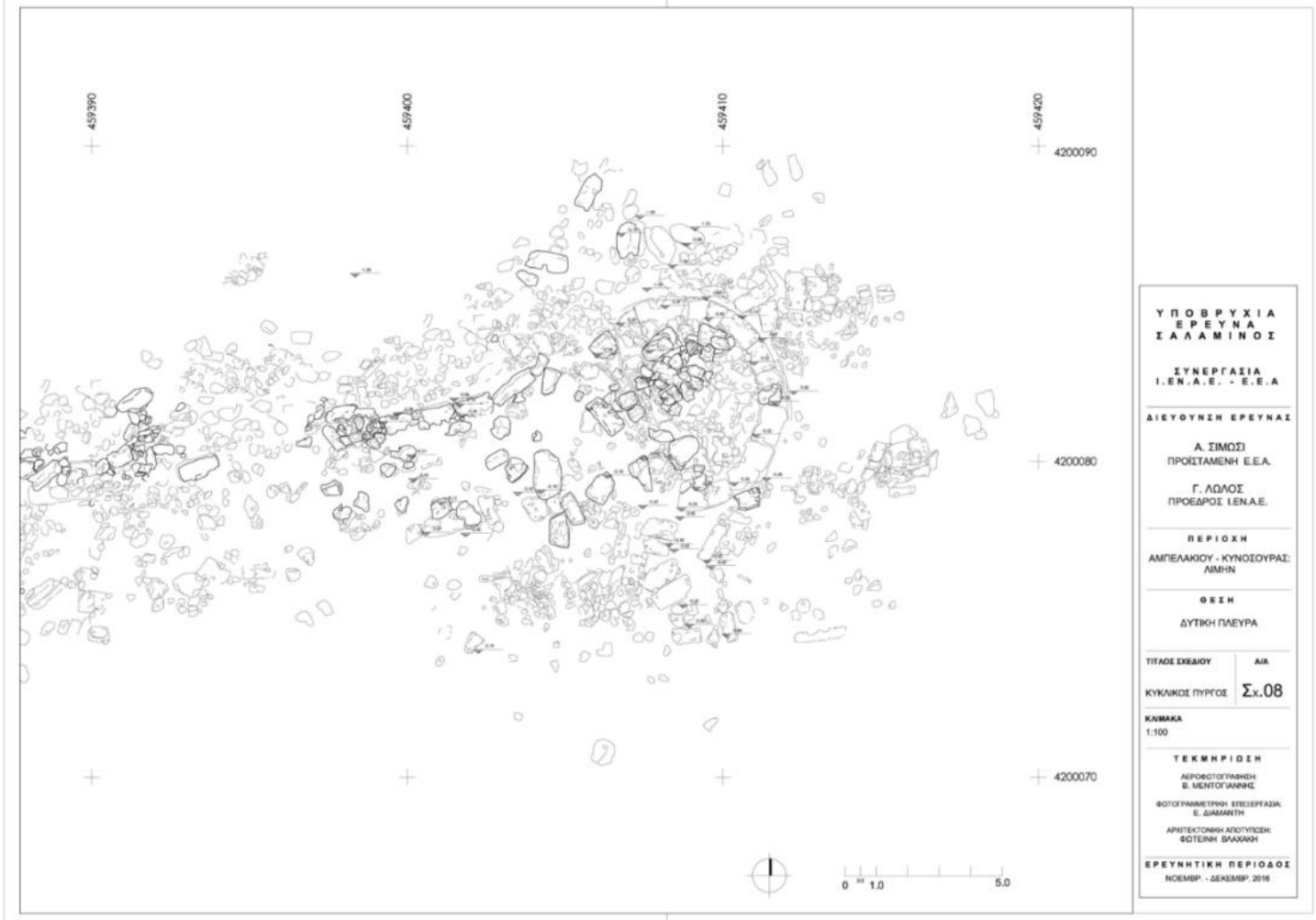

Fig. 13. Salamis, Bay of Ambelaki. Detailed plan of the remains of the round tower. 


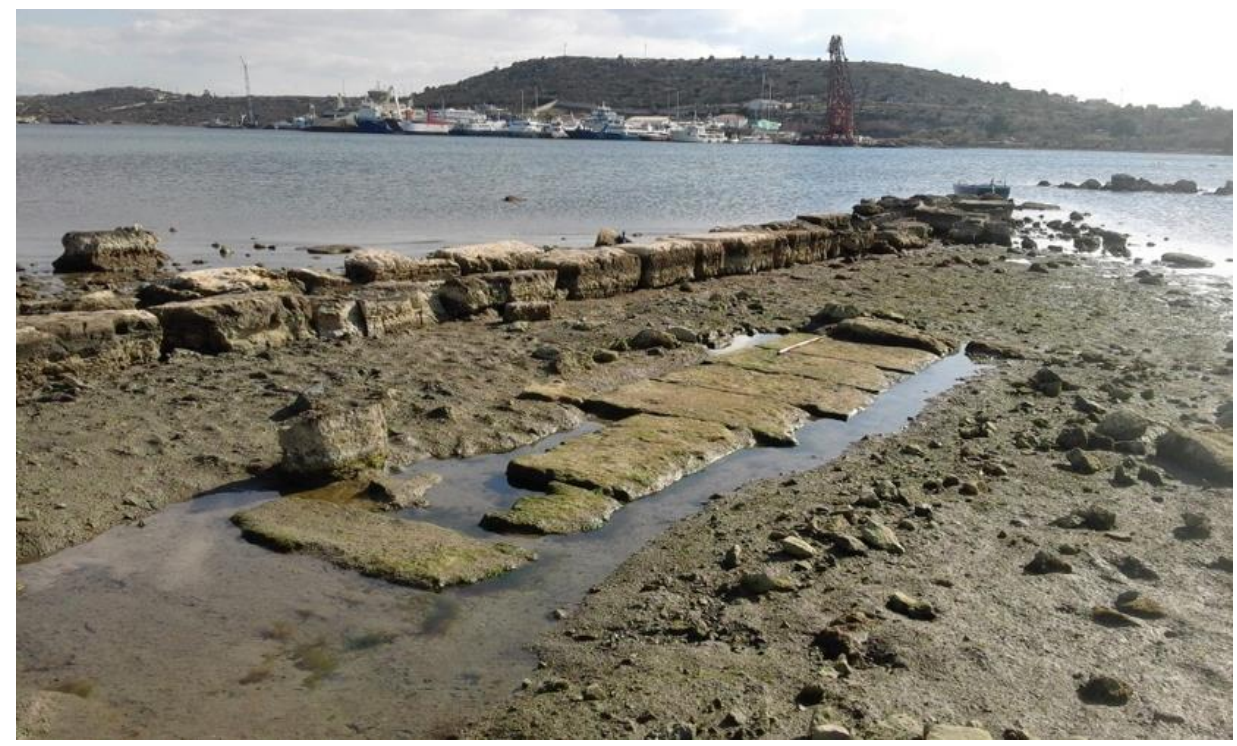

Fig. 14. Salamis, Bay of Ambelaki. Part of the foundation of a strong ancient building, close to a later (postRoman) mole, from north/northwest (2016).

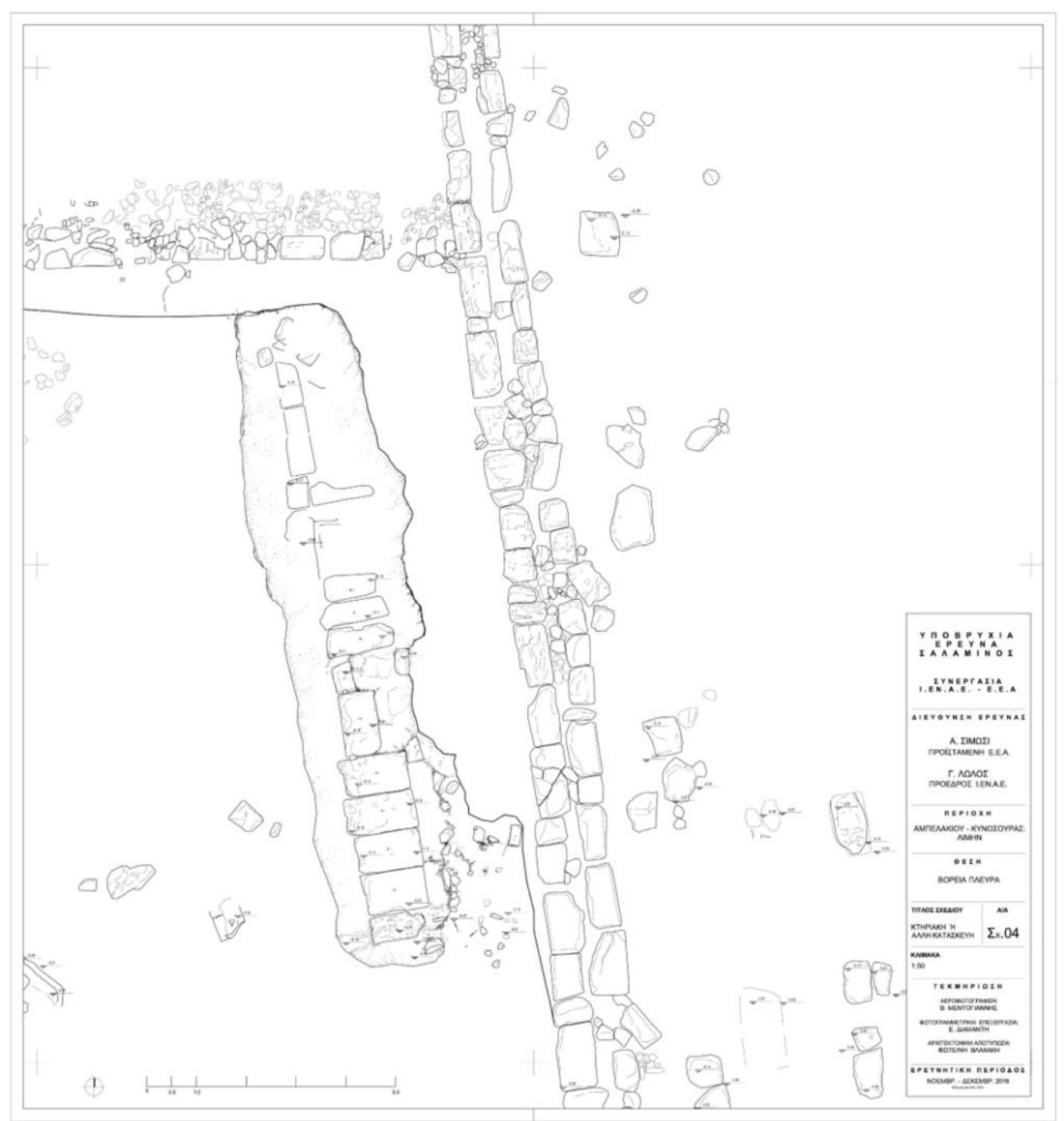

Fig. 15. Salamis, Bay of Ambelaki. Plan of the foundation course of a strong building, as revealed in December 2016. 


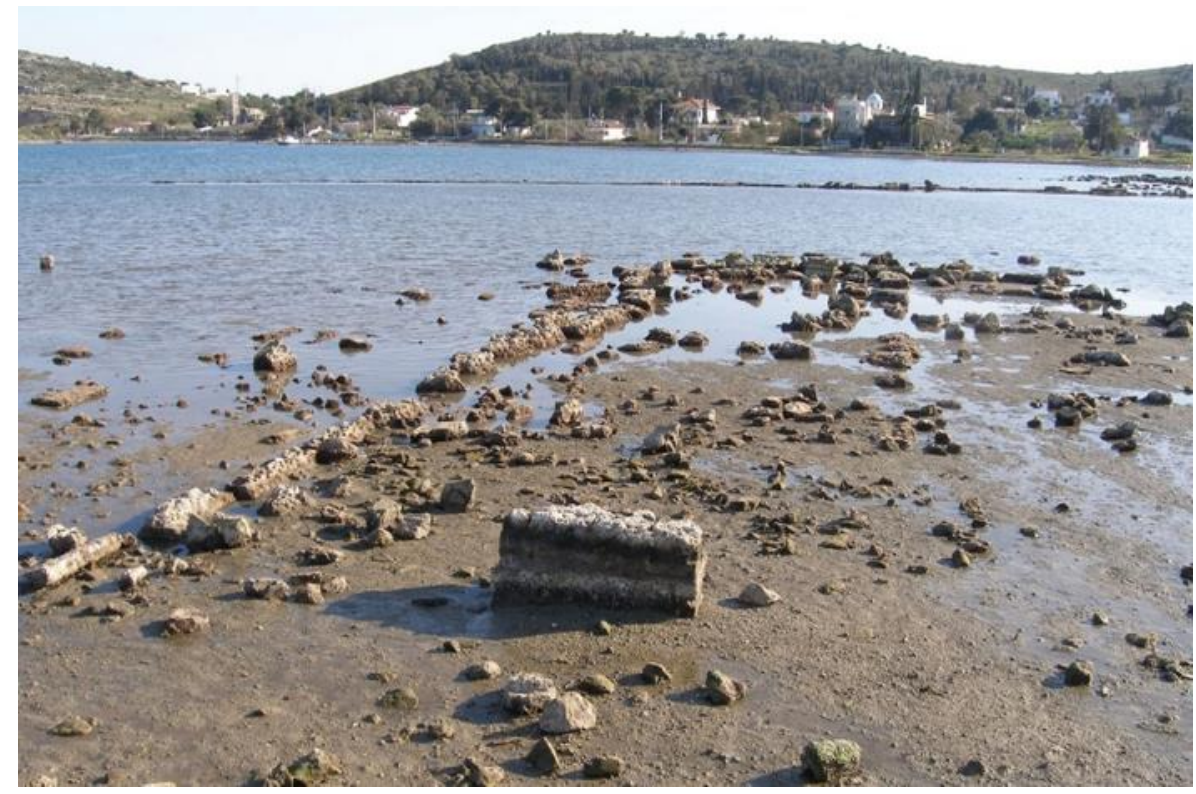

Fig. 16. Salamis, Bay of Ambelaki. View of large submerged building of oblong plan, in the northwestern part of the inner Bay, from north (2016).

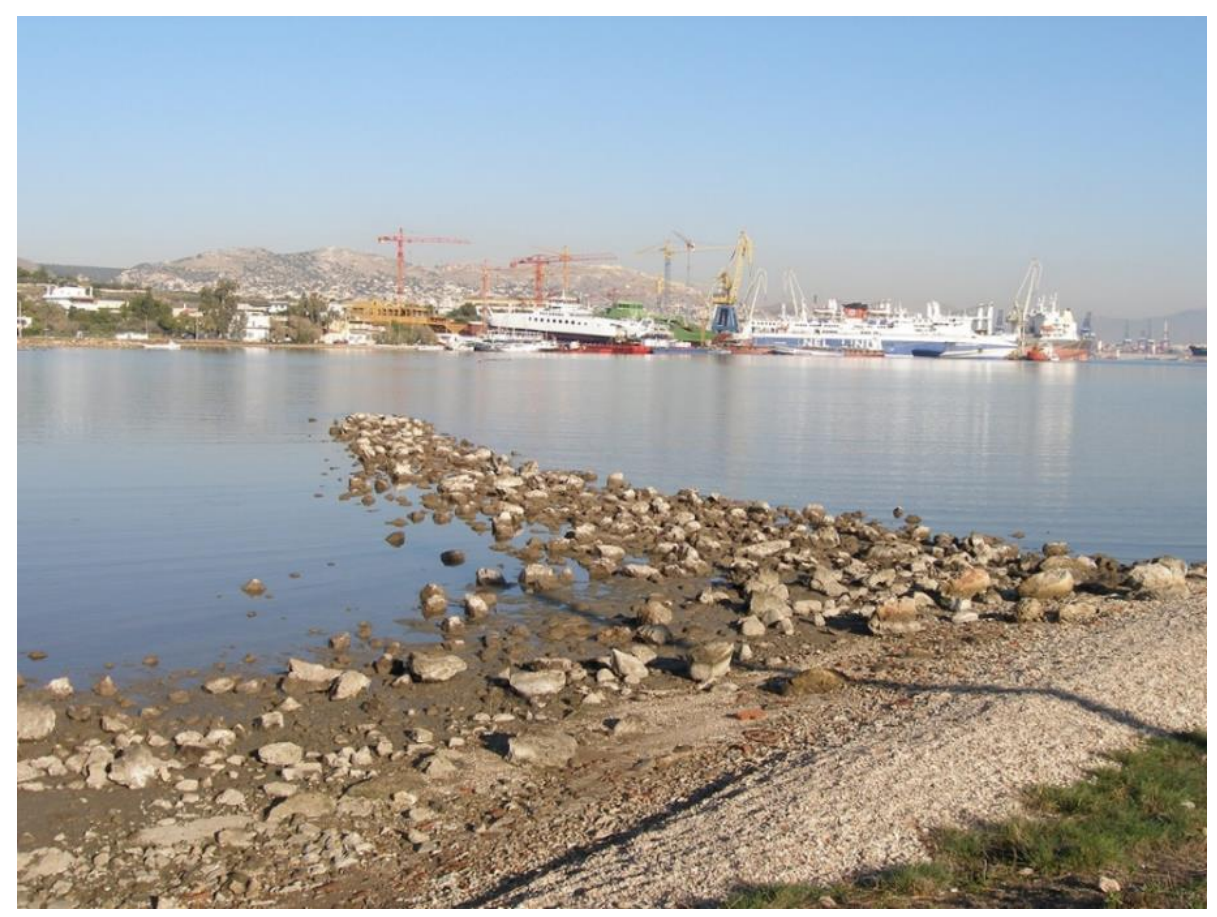

Fig. 17. Salamis, Bay of Ambelaki. View of a pier or breakwater of rubble, on the southwest side of the inner Bay, from southwest. 


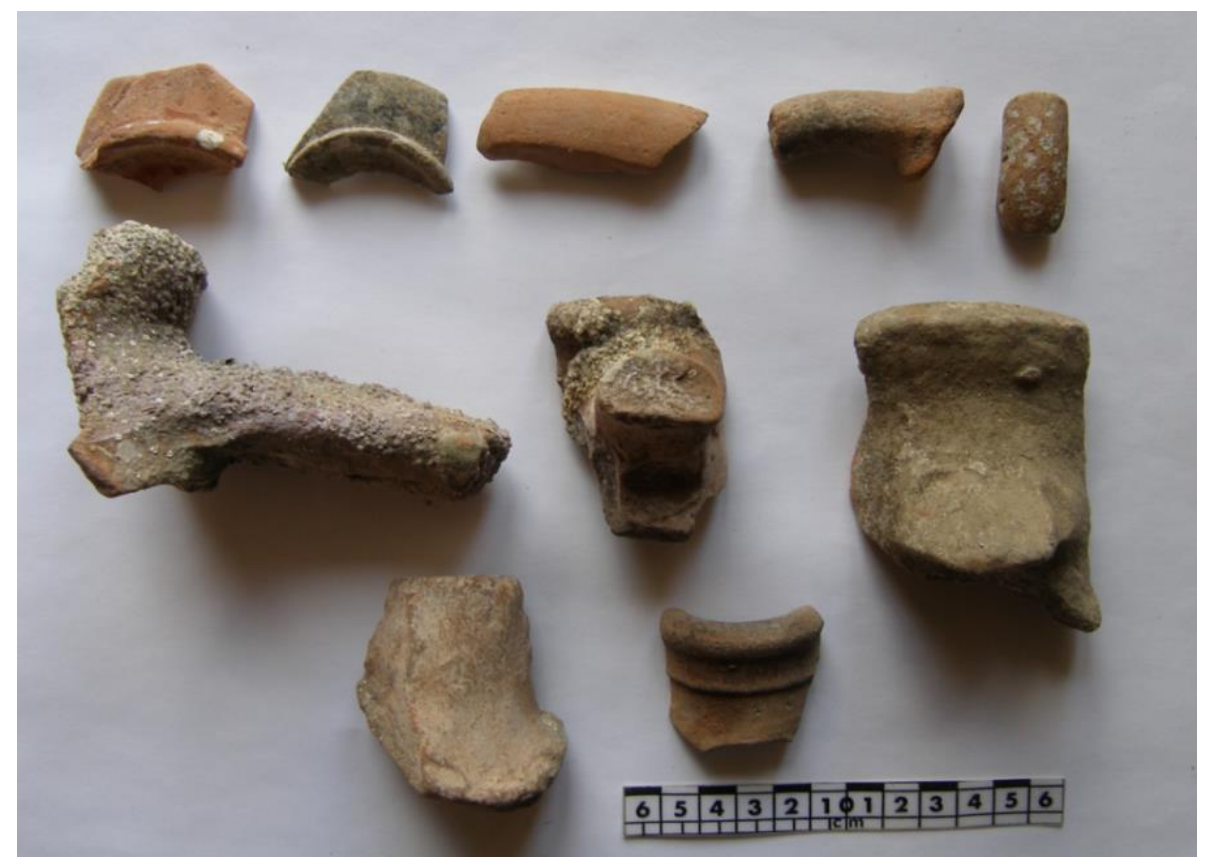

Fig. 18. Salamis, Bay of Ambelaki. Selection of potsherds, from surface collection (2016).

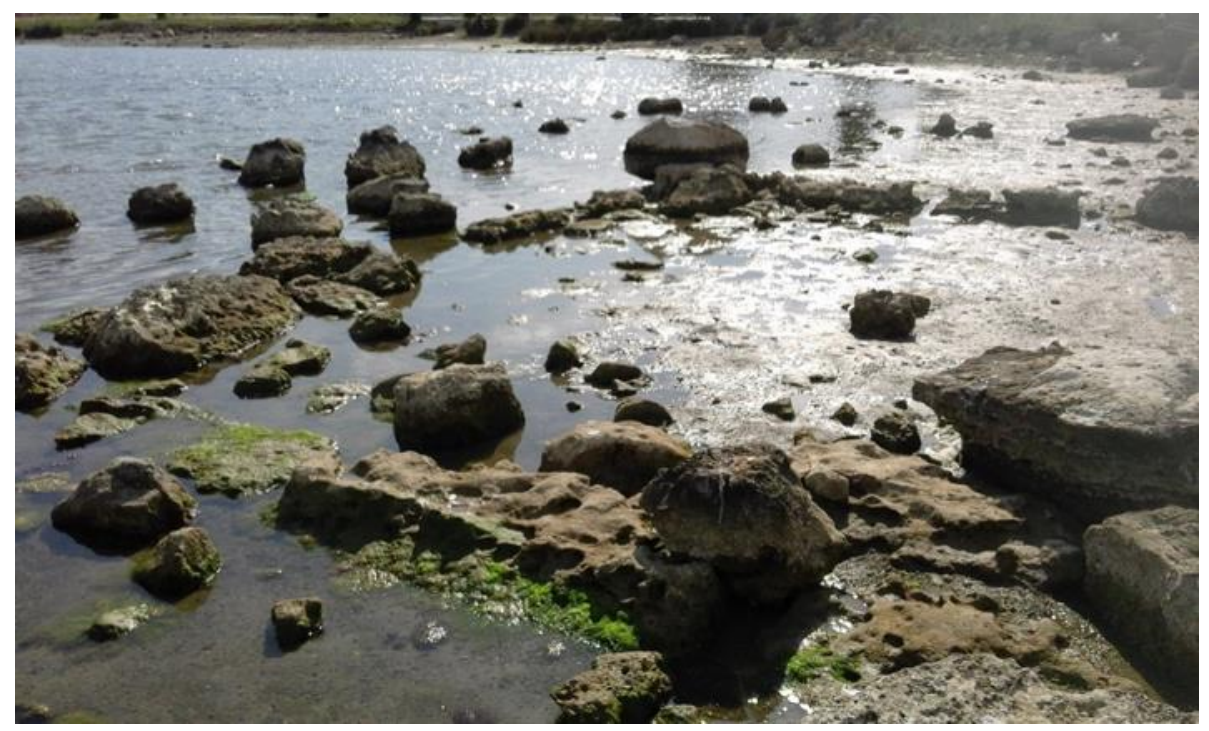

Fig. 19. Salamis, Bay of Ambelaki. View of the foundation of a square tower on the west side of the inner Bay, from northeast. 


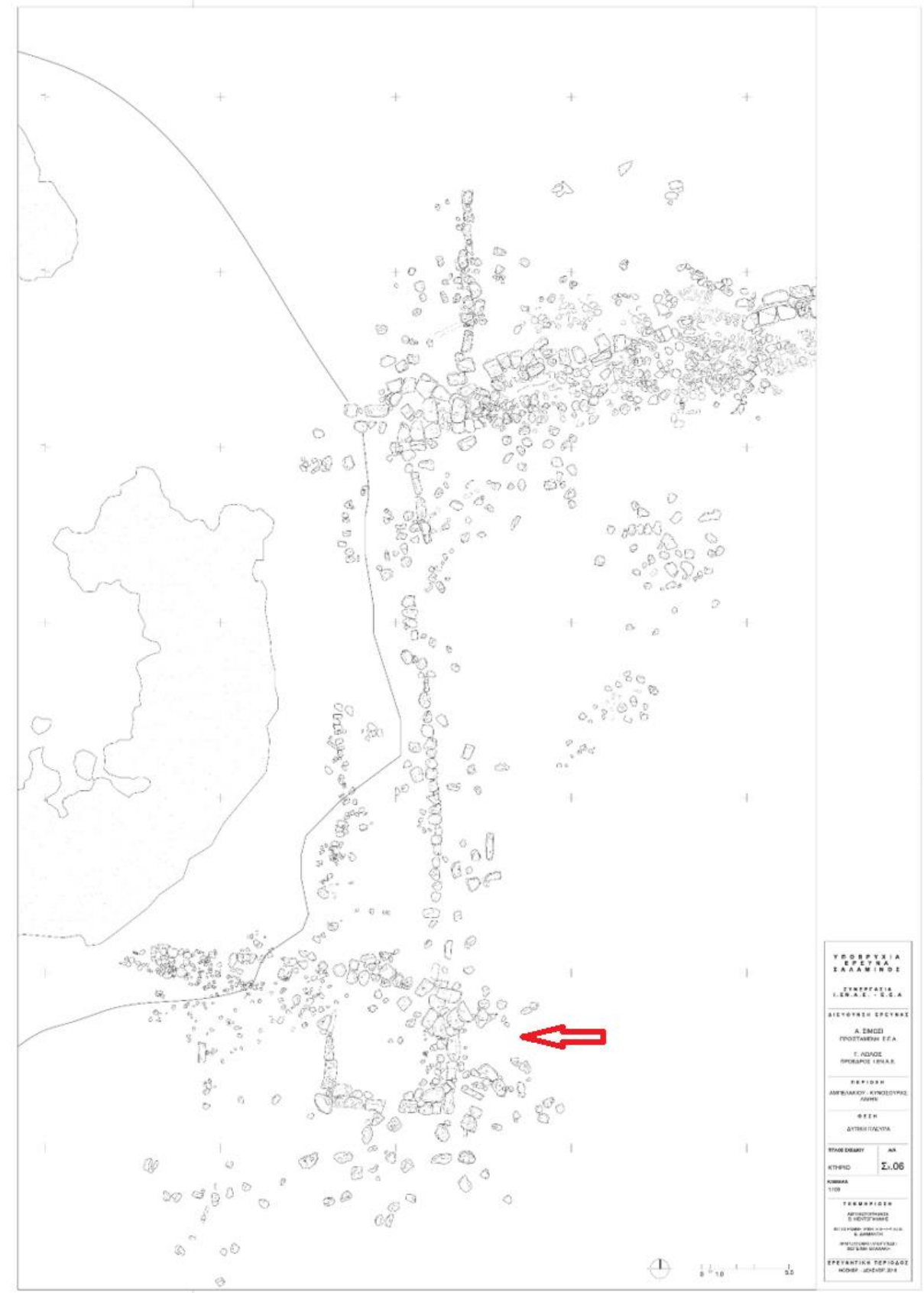

Fig. 20. Salamis, Bay of Ambelaki. Detailed plan of the area with the square tower, on the west side of the inner Bay. 


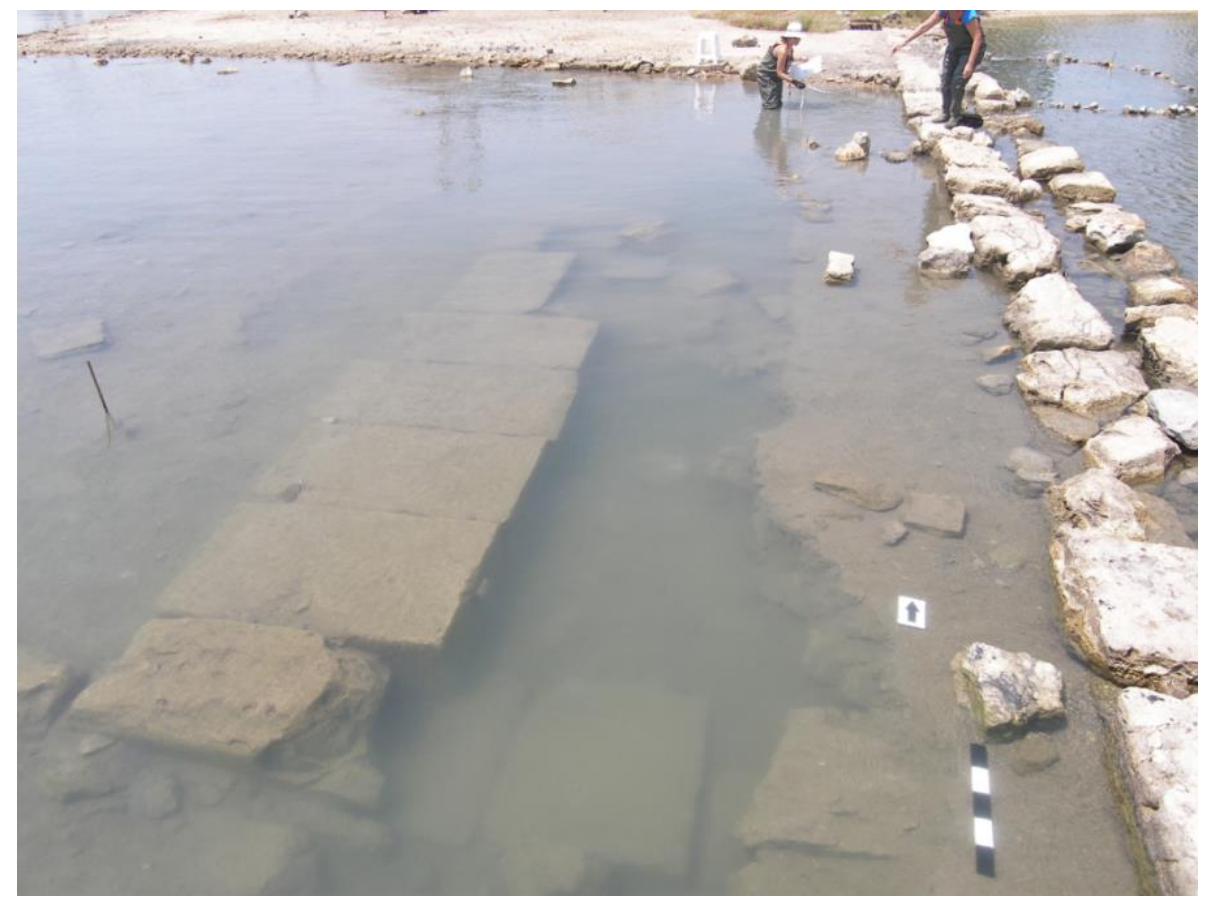

Fig. 21. Salamis, Bay of Ambelaki. View of the foundation of the public building, as revealed in July 2017, from south.

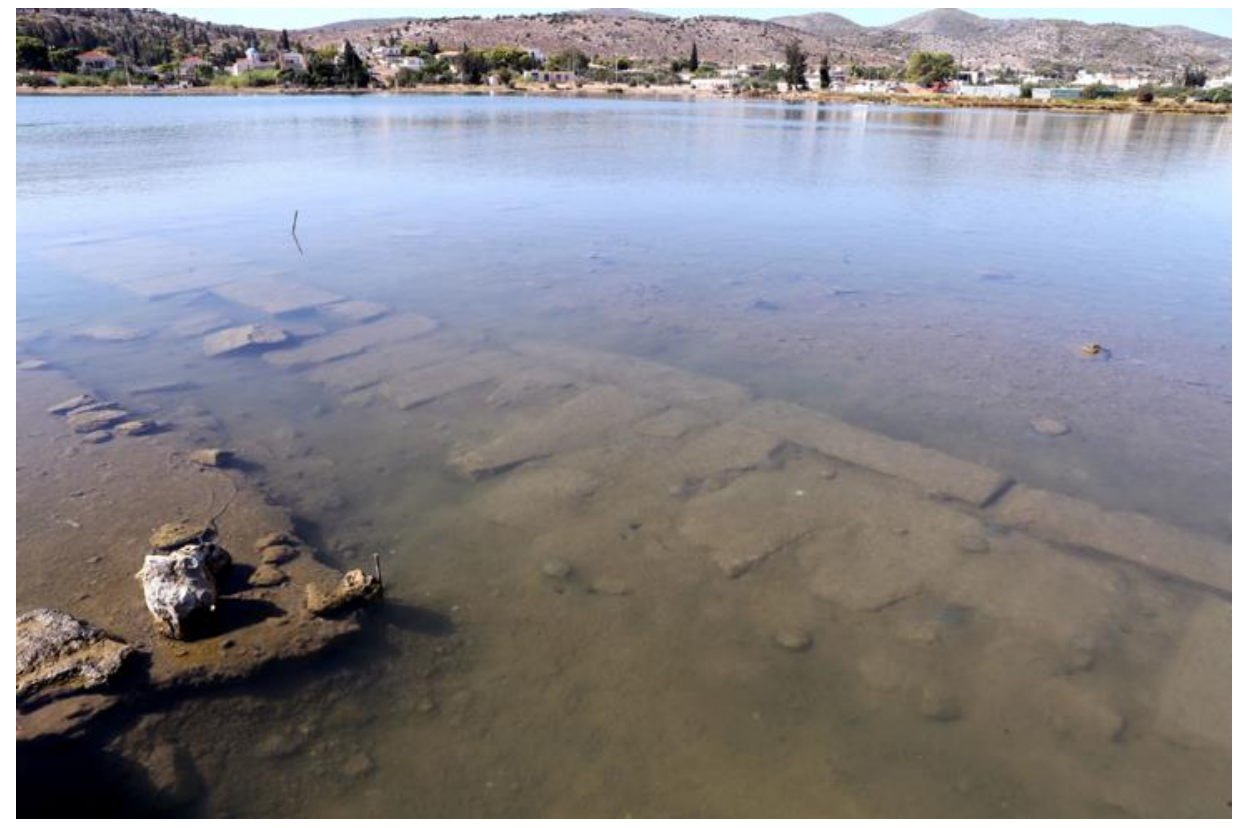

Fig. 22. Salamis, Bay of Ambelaki. View of the foundation of the public building, as revealed in July 2017, from northeast. 


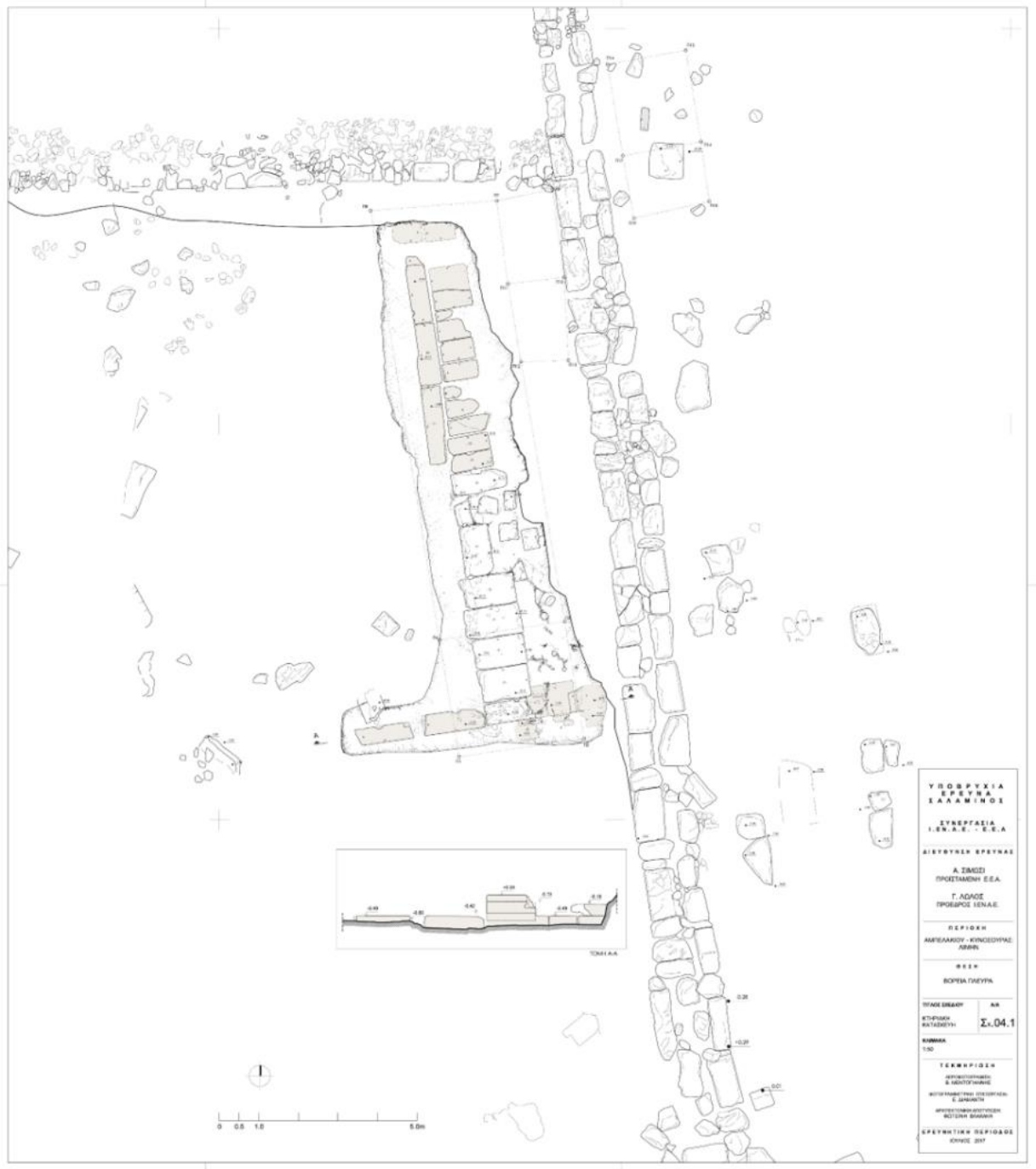

Fig. 23. Salamis, Bay of Ambelaki. Plan of the foundation of the public building, after the 2017 survey and clearing-work.

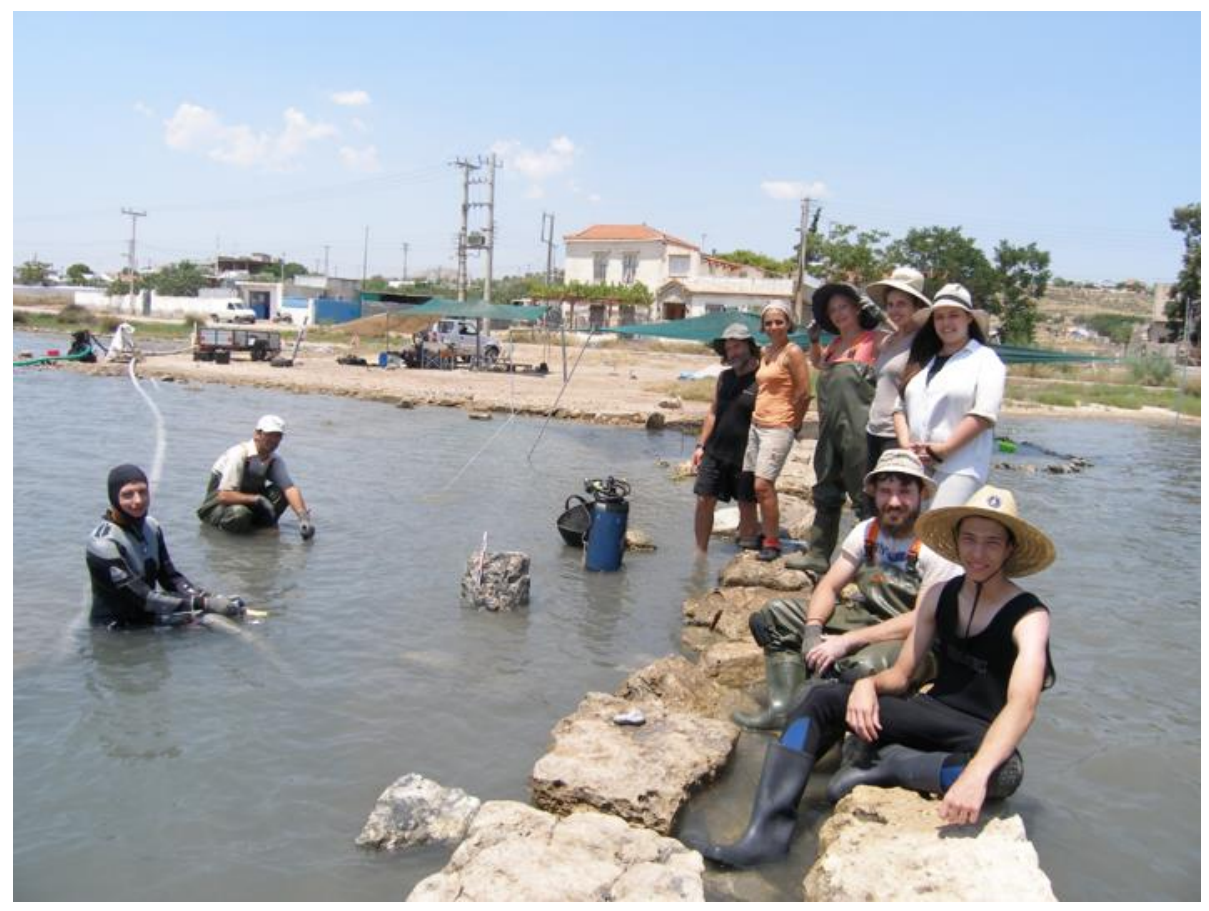


Fig. 24. Salamis, Bay of Ambelaki. Members of the team, around the drum of a stone column (2017).

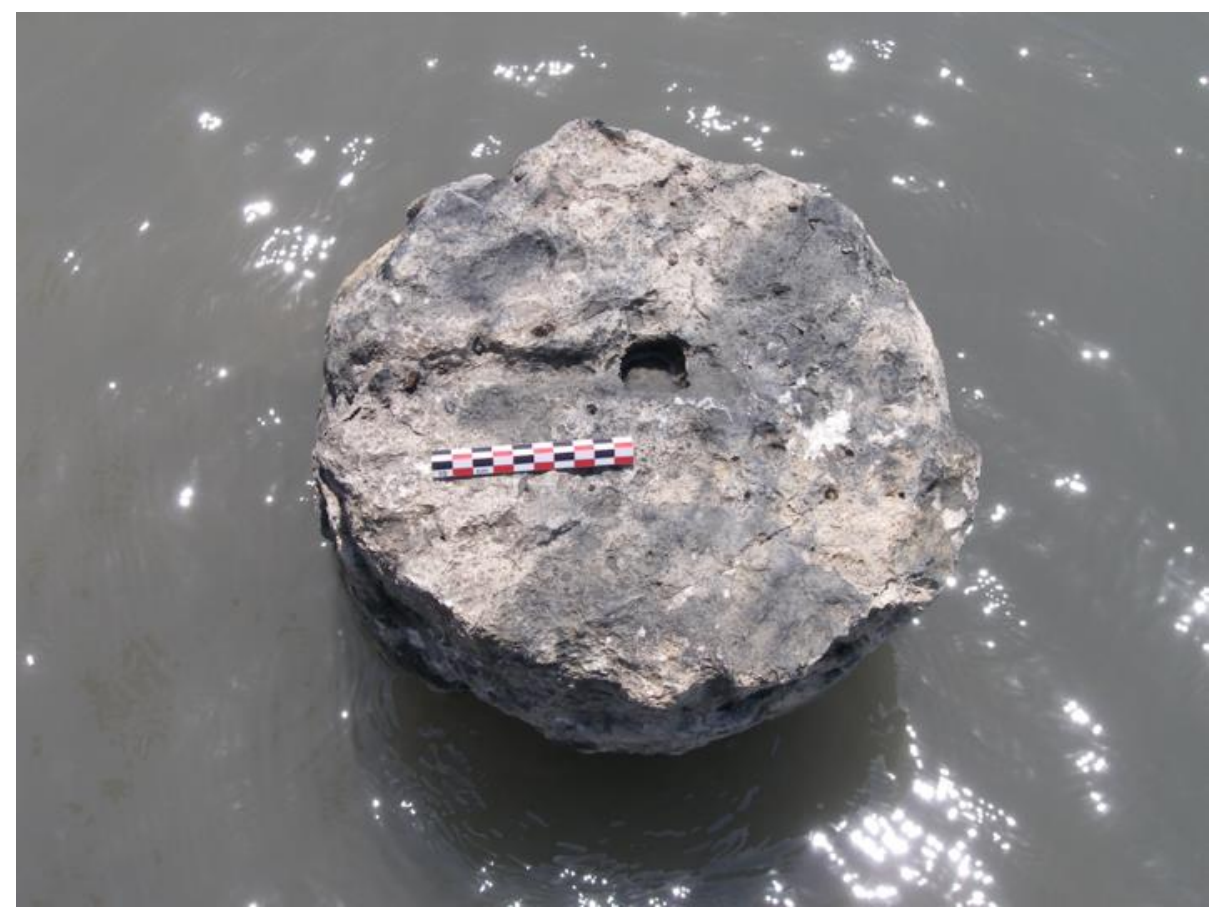

Fig. 25. Salamis, Bay of Ambelaki. Drum of stone column (view from above).

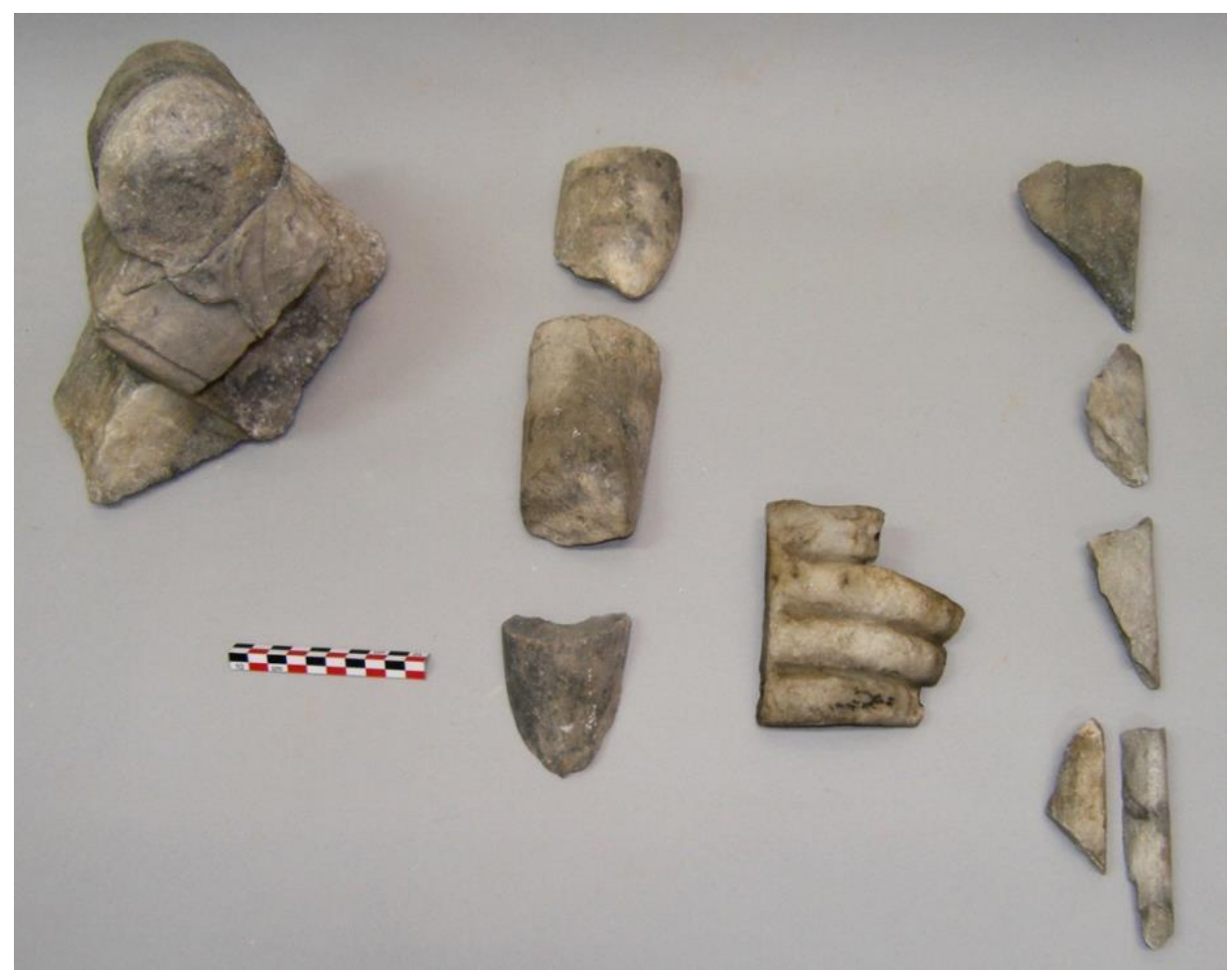

Fig. 26. Salamis, Bay of Ambelaki. Selection of marble finds from the clearing of public building: Fragments of altar and statue. 


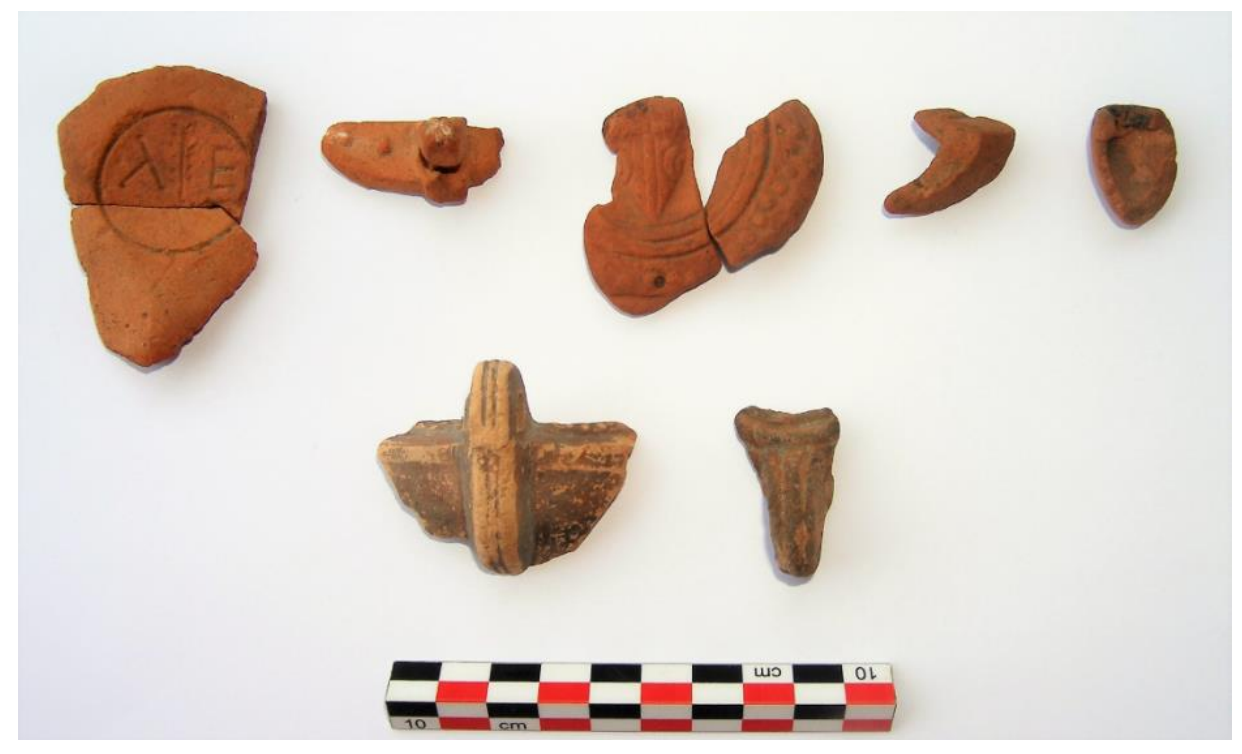

Fig. 27. Salamis, Bay of Ambelaki. Fragments of clay Late Roman lamps from the clearing of public building.

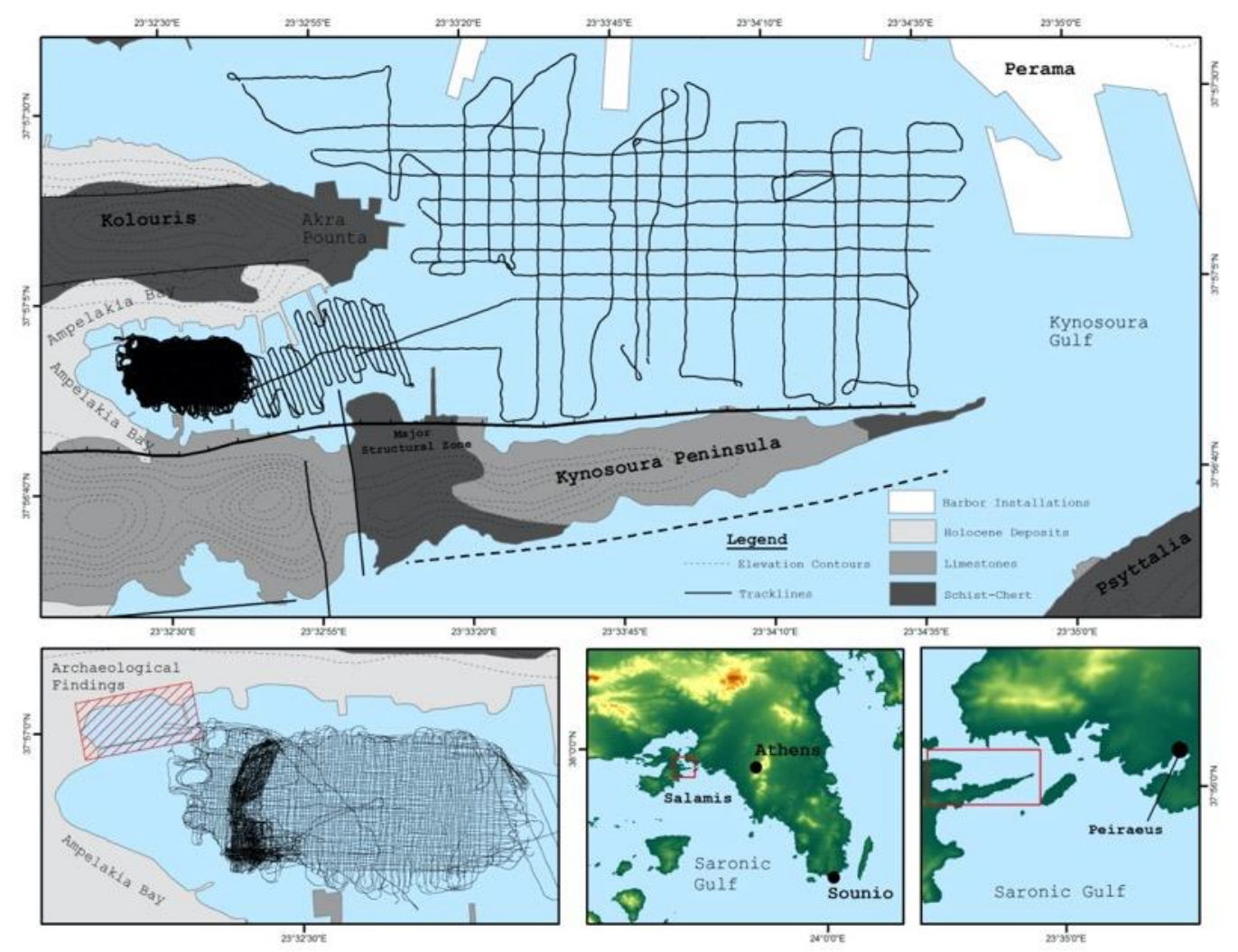

Fig. 28. Map showing the survey area and marine remote sensing tracklines. 


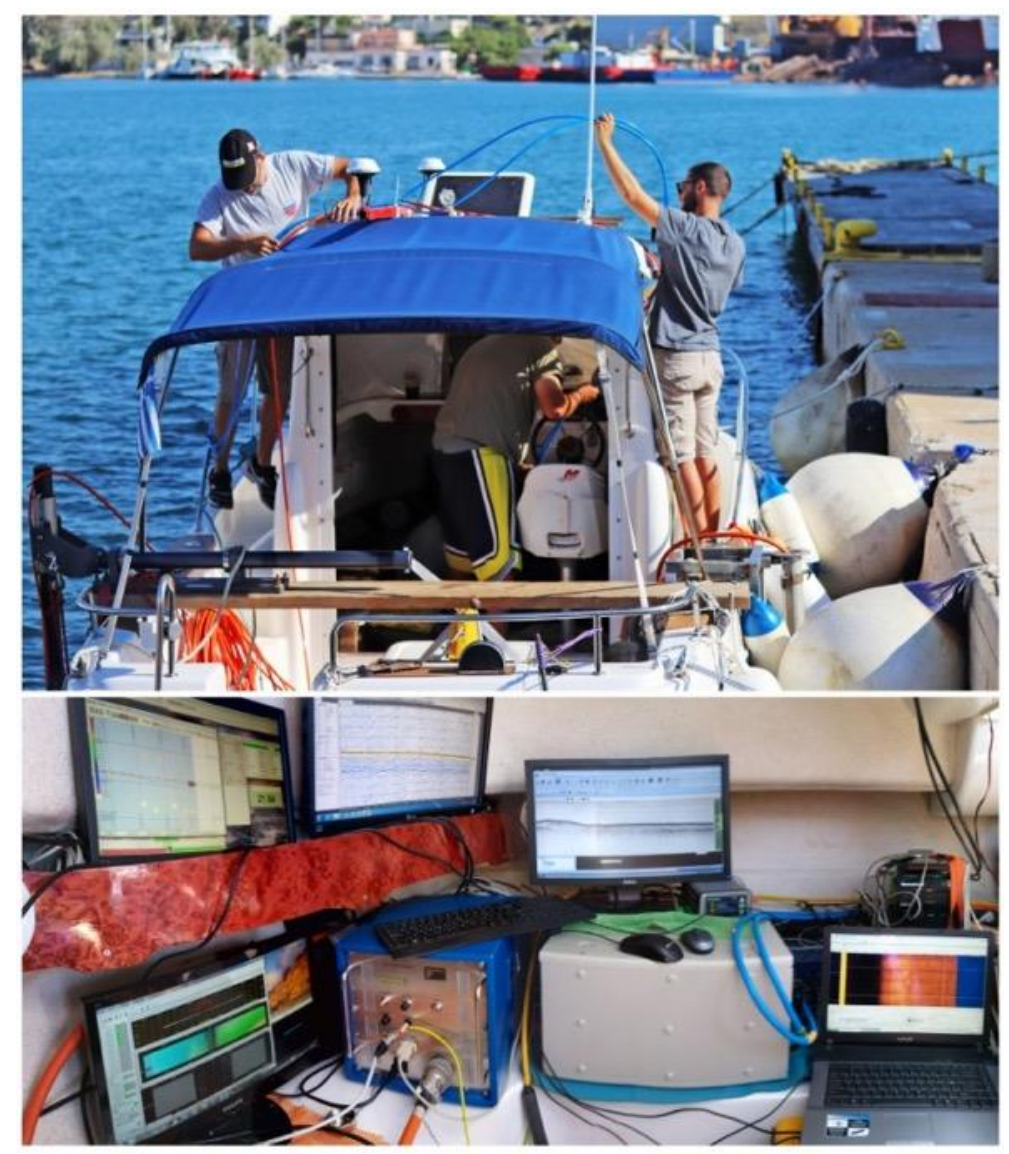

Fig. 29. Research vessel "Maria-Dimitra" and equipment set ups.

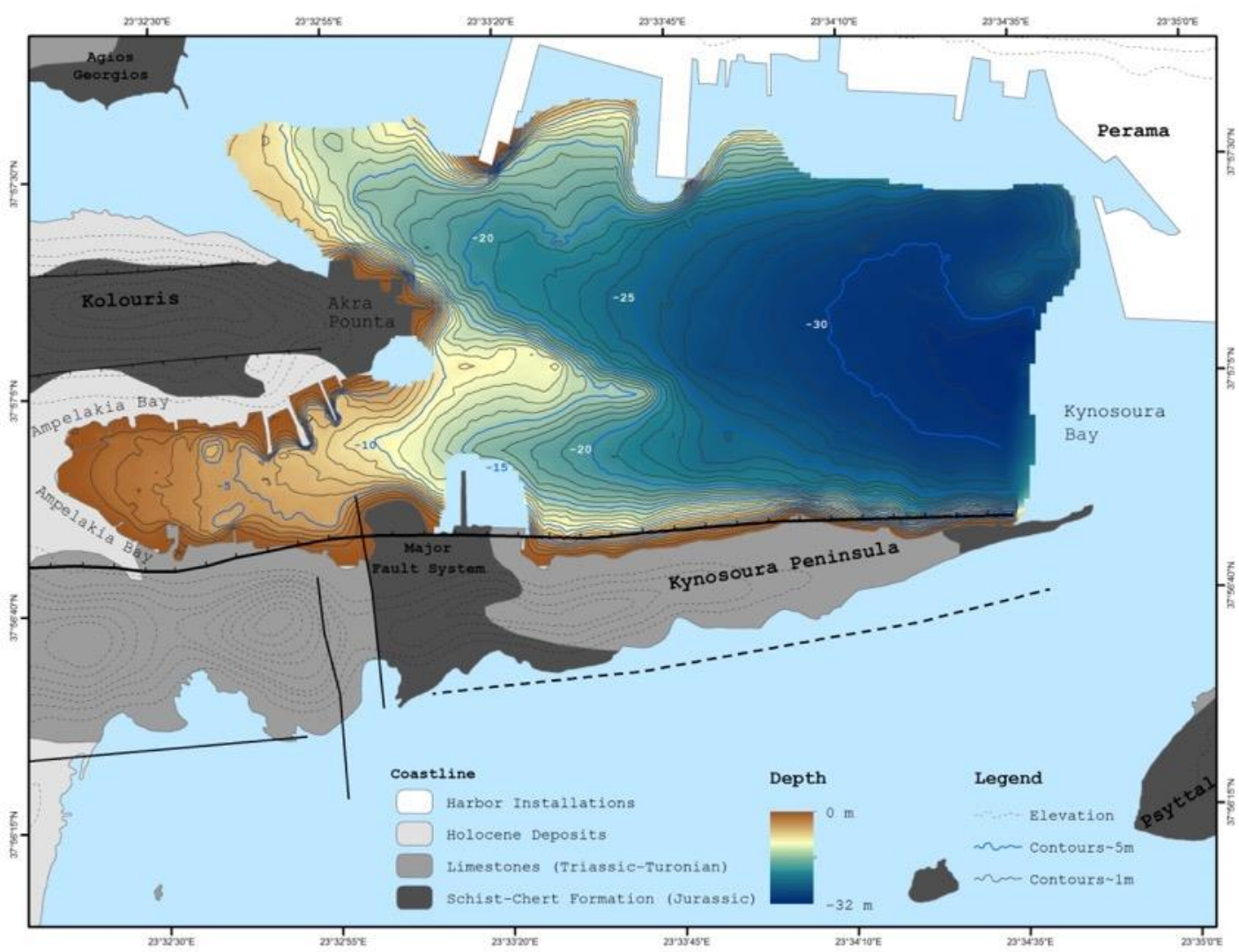

Fig.30. Bathymetric map of Kynosoura Bay. 

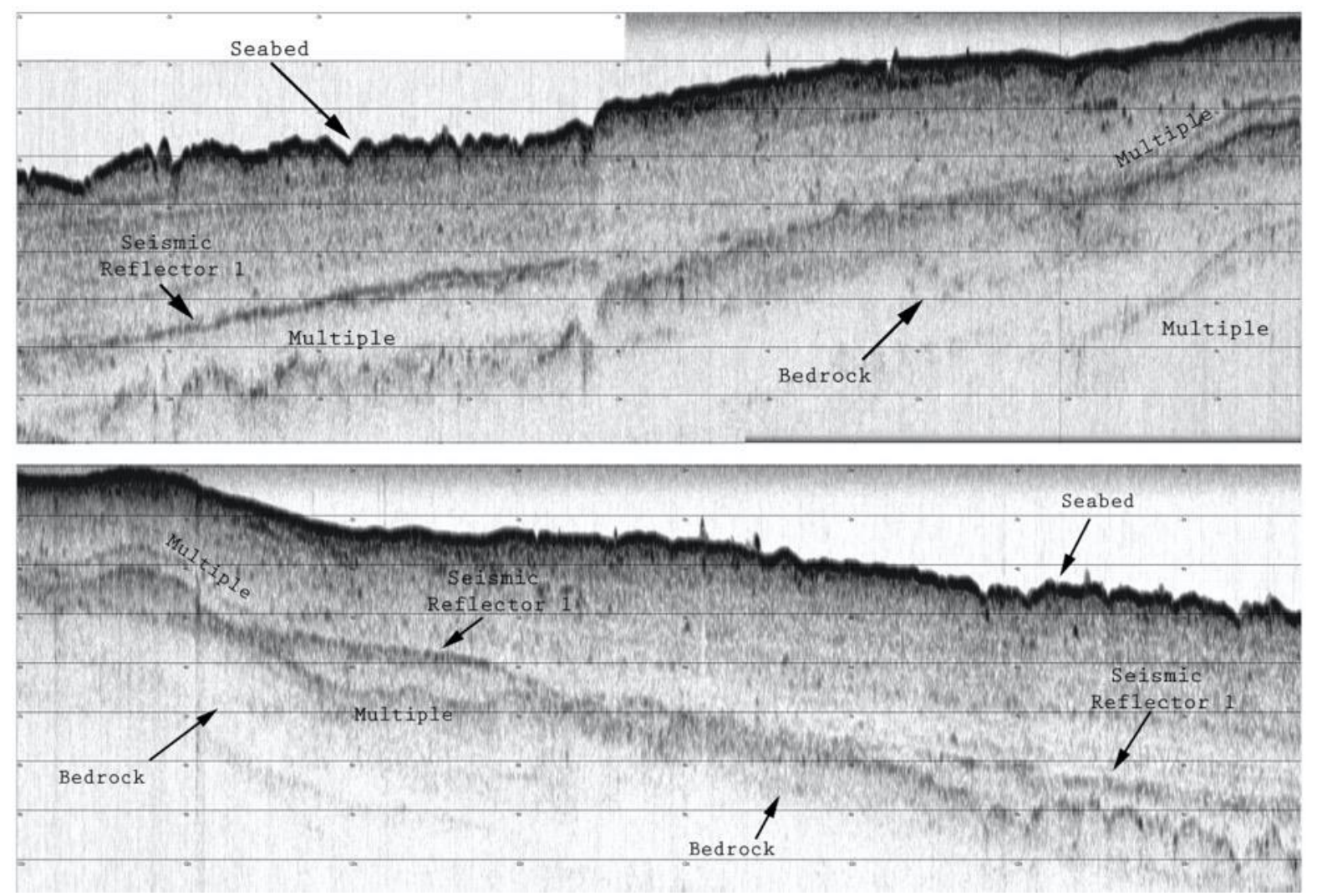

Fig.31. SES seismic profiles from the survey area showing the surface seismic unit and the Seismic Reflector 1.

Target A

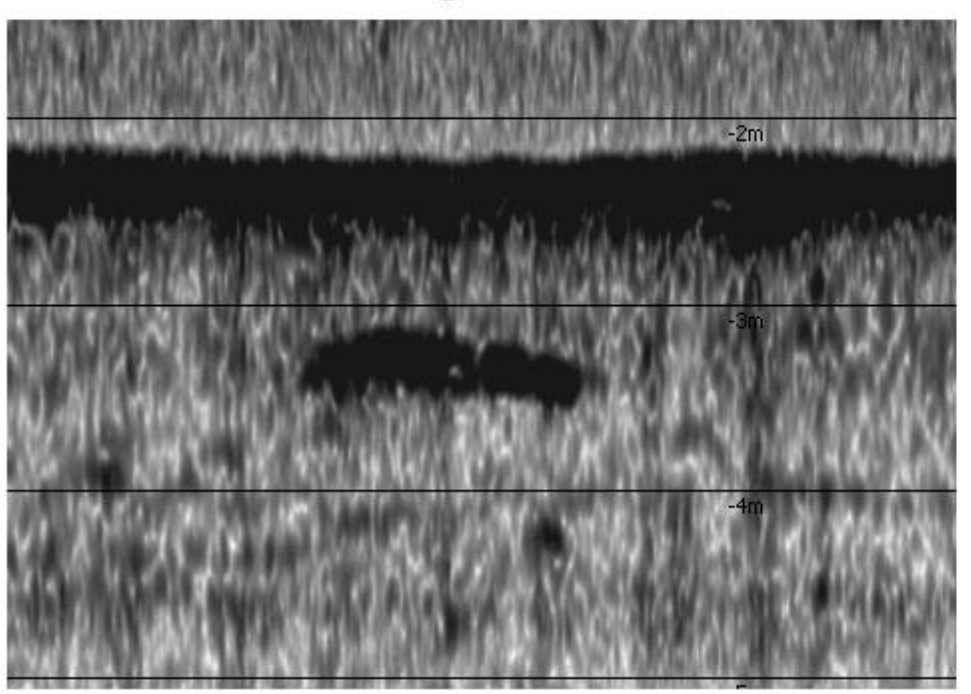

Target $B$

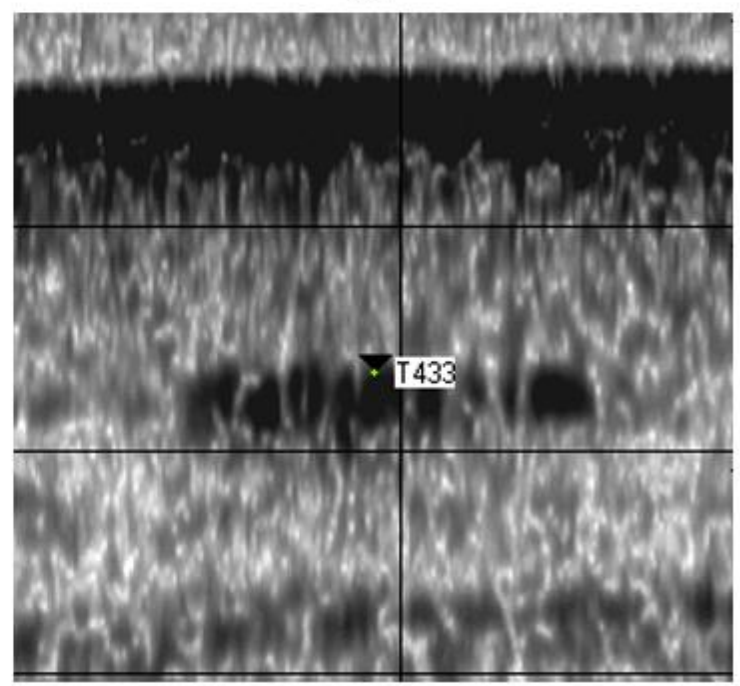

Fig.32. SES-2000 seismic profiles showing two promising targets (A \& B). 


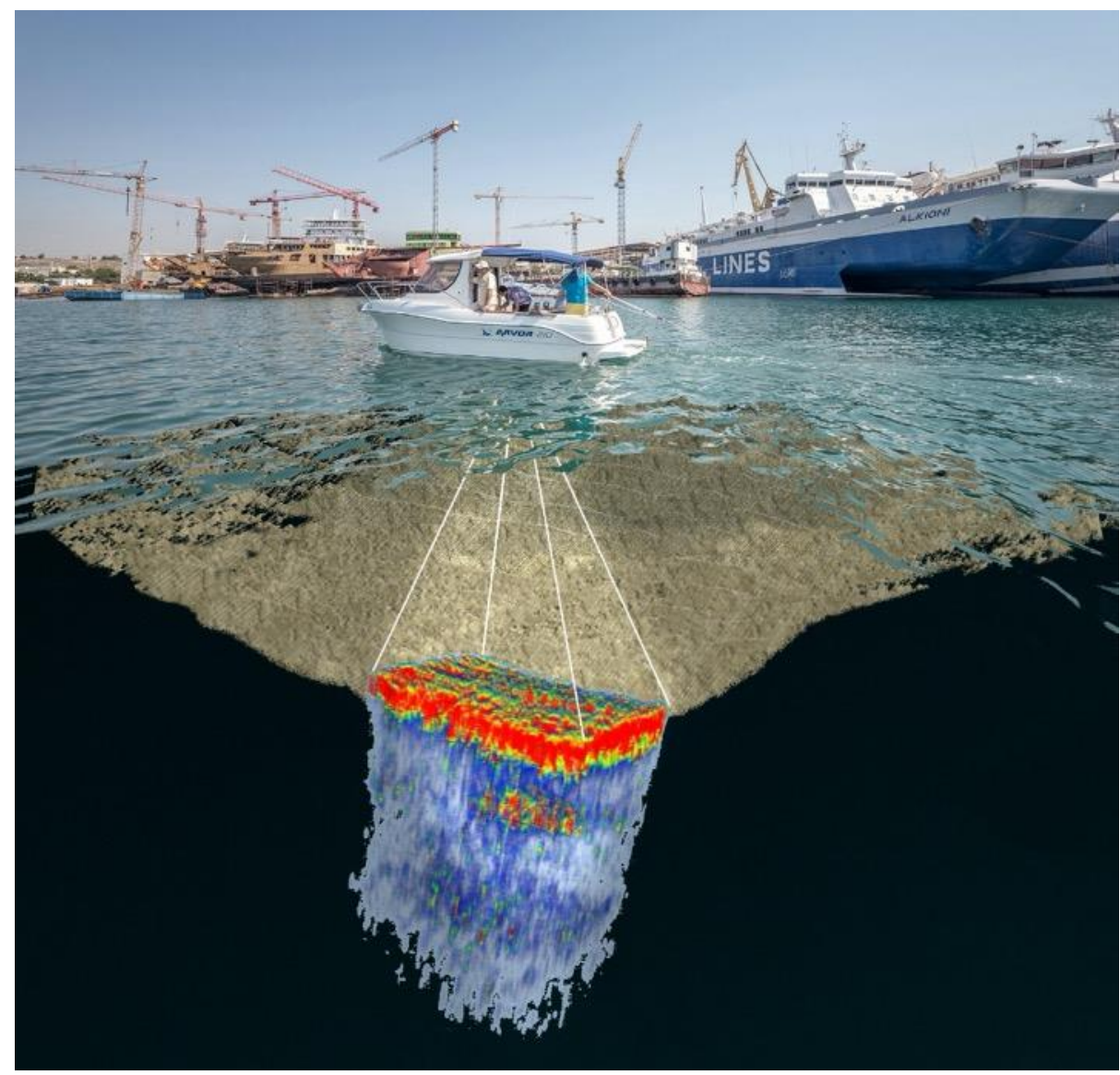

Fig. 33. Salamis, Bay of Ambelaki. 3D presentation by N. Georgiou of one of the most promising targets, buried in marine sedimentary deposits in the inner Bay (2017). 